\title{
Sensors and Systems to Enhance Aviation Safety Against Weather Hazards
}

\author{
PRAVAS R. MAHAPATRA AND DUSAN S. ZRNIĆ, FELLOW, IEEE
}

\begin{abstract}
Weather-related factors are among major causes of aviation hazards, passenger discomfort, poor airline schedule-keeping, and poor operating economy. A variety of new high-technology electronic sensors and systems for aviation weather are being developed and installed across the U.S. The aviation weather monitoring system of the future will be centered around Doppler weather radars which offer the best combination of coverage, resolution, and agility for this purpose, and are able to detect and estimate the severity of atmospheric air motion, including wind shear and turbulence, directly. Three major new Doppler radar systems are pertinent: the Next Generation Weather Radar, the Terminal Doppler Weather Radar, and the Airport Surveillance Radar with a dedicated weather channel. Other relatively simple new instruments for aviation weather support include the Low Level Wind Shear Alert System, the Doppler Wind Profilers, the Automated Weather Observation System, and the Automated Surface Observation System. These systems are designed to perform higher level functions such as detection, characterization, and hazard potential estimation of aviationsignificant weather phenomena, as well as their communication and display automatically. Together with conventional information sources and data from improved satellite imagers and sounders, the modern dedicated weather surveillance systems hold the potential of being powerful tools in enhancing the quality of aviation well into the next century.
\end{abstract}

\section{INTRODUCTION}

Throughout the history of organized aviation, safety has been the primary criterion in the design of aviation-related equipment and procedures. The Federal Aviation Act of 1958 defined the mission of the Federal Aviation Agency as [1] " . . to provide the regulation and promotion of civil aviation in such a manner as to best foster its development and safety, and to provide for the safe and efficient use of airspace." The safety problem has acquired a larger dimension in recent years as aviation operations have become more widespread, dense, diverse, and dynamic. With increase in the size and sophistication of airliners and the public visibility of air disasters, the cost of accidents (direct, compensatory, litigational) has been increasing rapidly in

Manuscript received May 25, 1990; revised January 9, 1991.

P. R. Mahapatra is with the Department of Aerospace Engineering, Indian Institute of Science, Bangalore 560012, India.

D. S. Zmić is with the Doppler Radar and Remote Sensing Research, National Severe Storms Laboratory, Norman, OK 73069.

IEEE Log Number 9102316. recent years. Air transportation touches our lives more intimately than ever before, and the aviation safety problem is no more merely a technical one; it is now an area of broad human interest. As in many other fields of human endeavor today, electronic systems hold the promise of contributing significantly to the mitigation of the problem, and are being increasingly used to fulfill that role. This paper attempts to discuss, in depth and breadth, the role of modern electronic sensors and systems in an important area of aviation, related to weather-induced factors.

In the initial years of aviation, the prime effort was devoted to ensuring the integrity and stability of the aircraft as a structural and aerodynamic entity. With growth in flight activities, the operational aspects of aviation started receiving increased importance. The main concern in this phase was to navigate individual aircraft reliably to reach its destination. This aspect soon became reliable enough to be taken for granted. As the skies got more crowded, the emphasis of aviation operations shifted to the avoidance of collisions and conflicts between aircraft sharing the same airspace. Ensuring the separation of aircraft remains the prime focus of air traffic control (ATC). A complex procedural framework, supported by instrumentation and communication network, has been built up in most parts of the world to ensure smooth flow of air traffic [2]-[4]. The system has been quite effective, making commercial aviation statistically among the safest forms of transportation [5].

With the collision problem effectively under control, the attention of aviation planners has turned toward other factors that continue to plague aviation safety and efficiency. Among these factors, weather-related phenomena have long been recognized as being the most important. A number of highly visible air disasters, and lesser known incidents in recent years, have been attributed to adverse atmospheric conditions. These, as well as weather-related delays and discomforts experienced by air passengers, have heightened the awareness and sensitivity of the general public, and the interest of aviation planners and the scientific community, regarding the role and the alleviation of weather effects on flight. Even apex scientific bodies such as the National Academy of Sciences have felt the need to devote specific 
attention to the subject [6]. Weather safety aspects are also given a high level of emphasis in the National Airspace Plan of 1981 [7] and its revisions/supplements (e.g., [8]) which form the blueprint for the evolution of the U. S. aviation system into the twenty first century. The report of the Aviation Weather Forecasting Task Force [9] identified many limitations of the present aviation weather system and provided recommendations for improvement.

In the recent years there has been rapid progress in the finer understanding of the nature of different types of aviation-significant atmospheric processes. The interaction of atmospheric processes with aircraft in flight, and the detection of severe weather phenomena, as well as the estimation of their hazard potential, have been the subject of concerted research during this period. The considerable knowledge base generated in the recent years has not only helped create a high degree of awareness in the aviation community regarding various aspects of weather effects on aviation, but has served as direct input to the design of advanced electronic sensor systems for surveillance of weather for aviation purposes. A number of such systems are currently in various stages of development and assessment. These are discussed in some detail in this paper.

Weather-related sciences-physical, observational and predictive-have evolved through long years of research, and have presently achieved a high degree of maturity. However, weather monitoring for aviation differs from most other weather applications (general, agricultural, hydrological, maritime, etc.) in several important aspects. Among them are the spatial and temporal scales of the phenomena of interest, and the expected agility of the surveillance system. Whereas general weather forecasting primarily deals with large scale phenomena (having characteristic dimensions of hundreds of kilometers or more) which are relatively stable and predictable, aviation may be strongly influenced by phenomena that are as small as a kilometer or less across, and which may arise and decay in a matter of minutes. Also, aviation operations are highly dynamic, requiring decisions (e.g., to land, take off, abort/divert/detour, shut down runway/airport) to be taken almost instantaneously, which means that detailed and updated weather information must be available to the decision-maker (pilot, navigator, or air traffic controller) in real time. Further, whereas general weather applications are overwhelmingly concerned with precipitation (and perhaps humidity and temperature), aviation is most profoundly affected by atmospheric air motions, including wind, wind shear, and turbulence [10], which may or may not be accompanied by precipitation, although heavy precipitation by itself may also be a disturbing or disrupting factor Finally, unlike most other branches of applied meteorology which essentially deal with phenomena as experienced close to the earth's surface, aviation applications require weather information at all altitudes at which aircraft may fly.

Because of such important differences from other weather applications, aviation weather has come to be regarded as a distinct (and rather multidisciplinary) area of activity, drawing from the field of atmospheric sciences, electronic
Table 1 Percent Accident Distribution In Aviation

\begin{tabular}{|c|c|c|}
\hline FLIGHT PHASE & $\%$ ACCIDENTS & $\begin{array}{l}\text { CAUSATIVE } \\
\text { FACTORS }\end{array}$ \\
\hline Taxi & 4 & Collision with object \\
\hline Takeoff and Climb & 35 & $\begin{array}{l}\text { Collision with terrain } \\
\text { Collision with plane } \\
\text { Pilot error } \\
\text { Mechanical failure } \\
\text { Inclement weather }\end{array}$ \\
\hline Cruise & 7 & $\begin{array}{l}\text { Collision with plane } \\
\text { Mechanical failure }\end{array}$ \\
\hline $\begin{array}{l}\text { Descent and } \\
\text { Approach }\end{array}$ & 27 & $\begin{array}{l}\text { Collision with terrain } \\
\text { Collision with plane } \\
\text { Mechanical failure } \\
\text { Inclement weather }\end{array}$ \\
\hline Landing & 27 & $\begin{array}{l}\text { Collision with object } \\
\text { Pilot error } \\
\text { Mechanical failure } \\
\text { Unsafe runway }\end{array}$ \\
\hline
\end{tabular}

technologies and aeronautical sciences. This fact has significant impact on the design of modern weather sensing systems. Aviation-related requirements have been included as important components in the definition of major modern weather sensors, and a number of special equipment and systems have been designed or planned entirely for use in aviation weather monitoring. These systems and their efficient utilization for the enhancement of aviation safety and efficiency are discussed in the paper.

\section{BACKGROUND: WEATHER EFFECTS ON AVIATION}

As aircraft fly within the atmosphere and are totally dependent on it for generating the forces that sustain and regulate flight, they are naturally influenced in major ways by the state of the atmosphere. In this section, we review the effects of various types of atmospheric phenomena on aviation.

\section{A. Weather as a Factor in Aviation}

A study of recent aviation history shows that weather factors can and do pose hazards to flight in many of its phases. Table 1 provides a summary of accident distribution in U.S. aviation [5]. It shows, not surprisingly, that only a small fraction of accidents occur during the cruise phase, in which aircraft generally spend a large part of their flight time. On the other hand, most accidents happen during the takeoff-climb or the descent-approach-landing operations. Weather appears as an explicit factor in Table 1 in those flight phases in which most accidents occur.

In fact, the role of weather in aviation safety is more significant than what is apparent from Table 1 . In addition to directly causing accidents, weather factors can contribute to, or enhance the probability/effects of, other factors listed in the table. For example, heavy weather and poor visibility may increase the possibility of pilot errors and collision with terrain or other aircraft. Mechanical or 
structural failure may result from excessive turbulence or hail. Similarly, heavy rains, ice covering, or wind shifts can render runways unsafe.

More specific studies have been conducted regarding weather effects on aviation. According to one survey [11] there have been as many as eleven fatal weather-related accidents involving U.S. air carriers alone between 1962 and 1984. In 1985, which was a particularly bad year for aviation with about 2000 airline fatalities globally, a high proportion of accidents were due largely to weather.

Whereas fatal air crashes, especially those involving large civilian airliners, are highly visible, inviting public attention as well as litigation, these are by no means the only effect of weather on aviation. Weather factors influence routine airline operations in more subtle but profound ways. Among these are passenger comfort, schedule-keeping and operating economy, which affect airline performance on a more continuous basis

Weather-induced rough flights, capable of causing serious discomfort and even injury, are a matter of common experience by many passengers. Equally common are delays attributed to weather factors. An early study [12] based on a large number (31 672) of flight delays revealed that over $85 \%$ of delays that are $30 \mathrm{~min}$ or longer were weatherrelated.

Accidents, incidents and delays due to weather (as those due to other factors) ultimately show up in the operating economy of airlines. (Incidents are events which come close to being accidents; these occur more frequently than actual accidents.) Apart from direct loss of aircraft and increased cost of insurance, litigation and compensation, there is loss of revenue due to reduced number of operations and loss of passenger confidence, and increased operating expenses due to in-flight holding necessitated by adverse weather conditions at airports which may make landing operations unsafe and/or slow. As early as a decade ago it was estimated [13] that the economic value of being able to forecast weather in the immediate future $(0-12 \mathrm{~h})$ at New York, Los Angeles, Chicago, and Denver airports alone would amount to about $\$ 25$ million per year. The figure would be significantly higher considering current cost and aviation activity levels. As another example, an estimate by the Transportation Systems Center in Boston indicates that the availability of real-time wind-shift information in the control tower at Denver's Stapleton Airport resulted in fuel savings of approximately $\$ 375000$ during a 45 -day period in 1984 [14]. In addition to direct cost to airlines, additional social costs accrue due to loss of productive time on the part of passengers. One estimate puts at $\$ 1.5$ billion the cost to the U.S. business community due to loss of productivity caused by delayed flights in 1985 alone [5], which included a significant fraction of weather-induced delays.

The management of flight operations to achieve the multiple goals of safety, comfort, schedule-keeping and economy simultaneously, from the weather perspective, is somewhat complicated by the fact that there exists a certain degree of conflict between some of these factors. For example, disasters due to bad weather could be largely avoided by the simple rule of avoiding takeoff, flight, and landing through regions of adverse weather [15], [16]. However, it has been argued on the other side of this proposition that if all weather zones possibly harboring phenomena that are potentially hazardous or uncomfortable to flight are to be routinely avoided, a very large number of flights would be disrupted, resulting in poor schedulekeeping and operating economy.

The general view of the aviation management community in the recent years has been that the optimal approach to meeting these conflicting goals is through a significant improvement in the quality, quantity, timeliness, and reliability of the weather observations available to the flight management system, along with short-period forecasts derived from such observations. The term "nowcasting" is used to describe such an "observation-intensive approach to local weather forecasting, with timely use of current data, in which remote sensing plays a dominant role" [17]. Thus an accurate nowcasting approach, dependent on sophisticated electronic systems for remote sensing, processing, display, and communication has dominated the recent developments toward achieving safety and efficiency of aviation in the weather context.

\section{B. Atmospheric Effects on Aircraft Flight}

Atmospheric phenomena of significance to aviation are of five major types: 1) phenomena involving the motion of air masses, including wind shear and turbulence, 2) hydrometeorological phenomena including heavy rain and hail, 3) icing, 4) low visibility, and 5) electrical phenomena. These phenomena affect aircraft in different ways, and each type has been known to cause serious air disasters, as well as frequent flight schedule disruptions.

There are two distinctly different phases of aviation operations, and aircraft have different levels of vulnerability to atmospheric effects during the two phases. The phases are:

1) The terminal area operations, which include takeoff, landing, taxiing, and parking. Air navigation in the terminal areas is characterized by high-density and dynamic operations involving low-altitude flights with minimum margins of speed and altitude to effect recovery when disturbances are encountered. Significant visual inputs are utilized in terminal area navigation, in addition to support from a number of modern navigational aids. For weather surveillance purposes, the Terminal Radar Control (TRACON) phase of ATC operations may be considered as a part of the terminal area operations.

2) The en route operations, characterized by relatively high-altitude and high-speed flights under nearly steady operating conditions and low traffic densities. Aircraft in flight usually dwell for relatively long periods of time in this phase with minimal pilot action. There are also high margins of speed and altitude for aircraft to recover from disturbances.

With this background, we now proceed to discuss the different types of atmospheric effects on aircraft flight. 


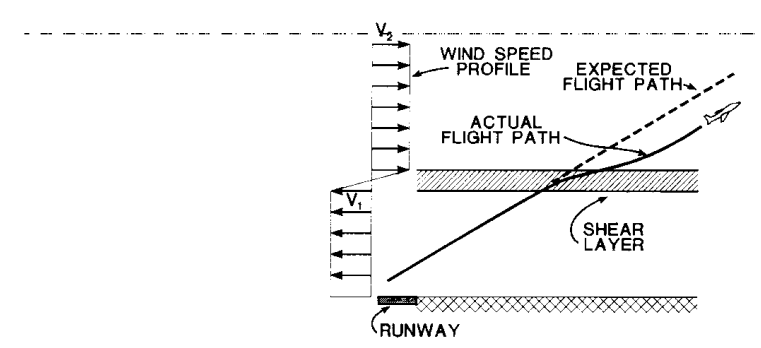

(a)

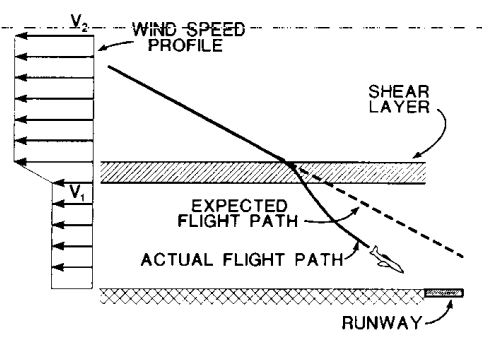

(b)

Fig. 1. General effects of vertical wind shear (vertical variation of horizontal winds) on aircraft during (a) takeoff and (b) landing. (Not to scale.)

1) Phenomena Involving Air Motion: Phenomena that involve the physical motion of air masses within the atmosphere affect flight directly. In this class the best known, and now most feared, is wind shear [18], [19]. A most general definition of wind shear refers to spatial as well as temporal rates of variation of wind speed and/or direction. In this sense, wind shear exists in the atmosphere nearly always at all points, but it becomes important for aviation only when it is of certain types and strengths. The destructive role of wind shear in aviation has been recognized as early as the fifties [20], [21], although the term "wind shear" was not in use in this context at that time. Through the subsequent years, as the phenomenon was better understood and came to be implicated in a growing number of air mishaps, its potential for disaster was recognized strongly enough to prompt a specific study by the National Academy of Sciences [6].

Because of the fast motion of aircraft through the atmosphere, the spatial and temporal variations of the wind velocity vector (as experienced by the aircraft) get coupled. Thus even in a field of steady wind velocities at each point (i.e., a field that appears steady, as opposed to gusty, to all static observers), an aircraft progressing along a trajectory may encounter time-varying wind velocities, and hence time-varying aerodynamic forces. Depending on the nature and severity of the force variation in relation to the state and characteristics of the aircraft, irrecoverable loss of control may result. Using the dynamical equations of aircraft motion, and mathematical models of wind shear [22], [23], it is possible to quantitatively determine the effect of wind fields on aircraft motion [24].

The basic nature of wind shear effects on aircraft is shown schematically in Fig. 1. Possible takeoff and landing scenarios are shown, with the aircraft moving in each case from a zone of lower tail wind to one of higher tail wind. The rapid increase in tail wind effectively reduces the air speed of the aircraft which often leads to loss of altitude relative to the expected trajectory. If the tail wind change is strong enough and persistent enough, the loss of height may be irreversible. As will be pointed out later, strong and rapid wind changes are indeed created by certain weather phenomena, notably divergent wind fields caused by thunderstorms.
Turbulence also involves the motion of air, but here the motion occurs over a different spatial scale. Turbulence consists of random eddy-like motion of different scale sizes. The passage of an aircraft through a turbulent field induces randomly oscillatory forces with a wide frequency spectrum. The spectral components of force important from the point of view of aviation safety and comfort are those that range from its structural vibration frequencies to its dynamical frequencies. In terms of spatial scales, this usually translates to eddy sizes of a few meters to several kilometers, the exact range depending on the size, type, and speed of the aircraft.

The most visible effects of turbulence are rough flights which most frequent passengers encounter at one time or another. Turbulence of relatively low frequencies, which excite the rigid body dynamical modes of the aircraft, can lead to difficulties in controlling the aircraft or even loss of control, causing accidents [25]. It may also induce rapid lateral accelerations, leading to dislocation of objects and passengers within the cabin. This may result in passenger injuries, often quite serious [26]-[29], even though the aircraft itself may not be visibly damaged. In extreme cases, however, the forces induced by turbulence may be so strong as to cause actual structural breakup of aircraft in flight as a result of high stresses and/or metal fatigue [30], [31].

Further, flight through fields of turbulent air causes the airflow into the aircraft's jet engines to vary randomly, resulting in a erratic variation of propulsive force or thrust. Such a thrust variation further accentuates the problems with the control of the aircraft.

2) Hydrometeorological Phenomena: Hydrometeors are particulate matter consisting of different forms of water that fall through the atmosphere under the force of gravity. Their fall speeds and direction are also influenced by atmospheric drag and the local air currents. The most commonly encountered members of this family are rain, snow, and hail.

Rain in low or moderate intensities does cause some visibility problems, but aircraft design and navigation procedures and aids have been perfected to a point that such rain has ceased to be a significant threat to aviation. Rainfall of high intensity can, however, be highly detrimental to 
aviation. One major effect of heavy rain is interference with the combustion process within aircraft jet engines. Ingestion of significant amounts of liquid water along with the air entering the engines results in erratic combustion and thrust reduction. In extreme cases flame extinction or "flameout" may occur, leading to total loss of engine power [32], [33].

Recent research has further revealed that heavy rain may also cause significant impairment of aircraft performance (i.e., reduce lift and/or increase drag) by aerodynamically roughening the wing surface in a manner analogous to ice or frost [34]-[36]. In the case of the well-known Pan American Boeing 727 crash at New Orleans in 1982, detailed analysis [37] has shown that the inclusion of lift loss and drag increase due to heavy rain in addition to wind shear effects is able to explain the recorded flight parameters better than wind shear alone, which was officially determined to be the probable cause of the accident [38]. The problems due to lift loss and drag increase may be further aggravated by momentum loss on the part of aircraft by the physical impact of large quantities of hydrometeors.

Besides these direct effects of heavy rain on aircraft flight, and other obvious effects such as very low visibility and hydroplaning on wet runways, a high level of rain activity also adversely influences aviation by impairing the performance of many instruments on which navigation is dependent. Among such instruments are the landing guidance systems [39] and radars. The precipitation-induced attenuation of the X-band airborne weather radar, and the resultant degradation in its ability to detect the extent and intensity of the weather disturbances, have been determined as factors contributing to the cause of the air crash in Nebraska in 1980 [33].

Snowflakes do not directly cause damage to aircraft. However, the effects of snow storms such as poor visibility and slippery runways are of concern to aviation. Wet snow tends to get deposited on aircraft, which along with ice accumulation, has been implicated in at least one serious accident [40]. Also, snow storms are among the frequent causes of airline delays and schedule disruptions in the winter season.

Hail, in contrast, can be highly detrimental to aircraft. Along with rain water, the ingestion of hail into jet engines contributes to erratic combustion, flameout and the resulting loss of thrust [32]. Hail ingestion can also damage delicate moving parts of the engine such as the fan and compressor blades. Large size hail can cause extensive structural damage to the exposed parts of aircraft such as wind shields, canopies and the skin of the leading edges of the wings and control surfaces, as dramatically illustrated in the photographs in Fig. 2.

3) Icing: In the context of aviation, icing refers to the accretion of ice on certain parts of the aircraft, especially the leading edges of wings and stabilization/control surfaces, which disturbs the air flow over these surfaces, resulting in impairment of aerodynamic performance. The severity of aircraft icing and its influence on aircraft performance are dependent on temperature, liquid water content, and
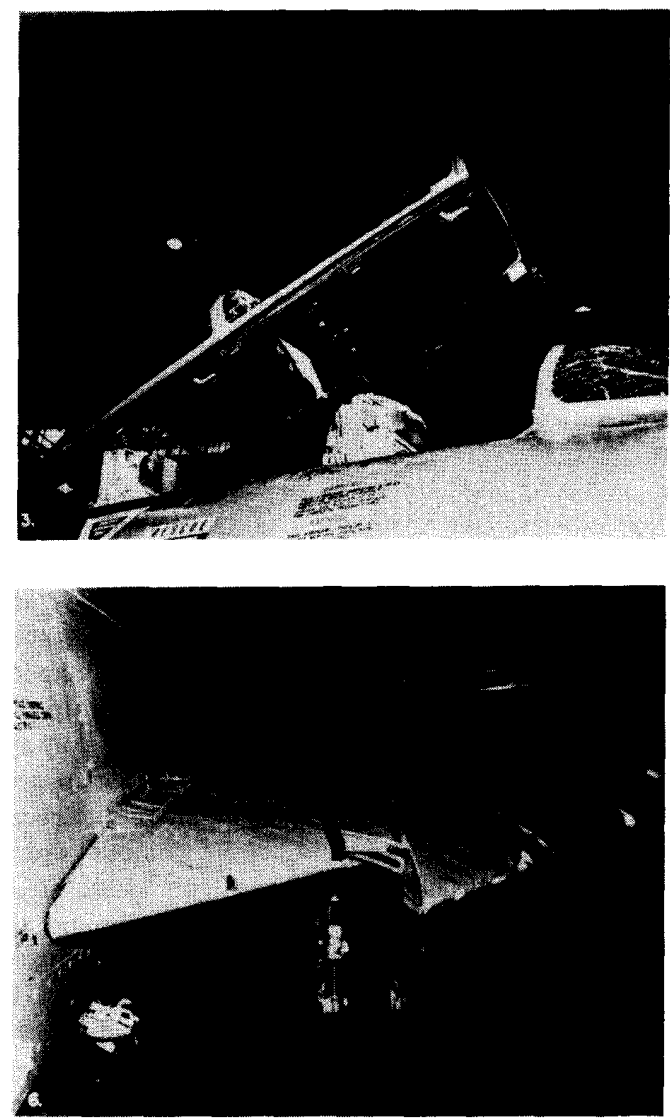

Fig. 2. The damage to a military aircraft canopy (top) and wing leading edges (bottom) caused by hail impact during flight. (Photos courtesy of Jean T. Lee.)

cloud droplet size distribution in the ambient air, turbulence level, water phase, and the type and flight condition of the aircraft [41]. In particular, flight environments characterized by the presence of supercooled liquid water (water that exists in liquid form below the freezing temperature) are highly conducive to icing, because such water can freeze immediately on impact with the aircraft skin or preexisting ice layers. Most serious aircraft icing hazards occur when supercooled liquid droplets grow to diameters of $30-400$ $\mu \mathrm{m}$ [42], [43]. It has been demonstrated that the rate of climb capability of several research aircraft declined by more than $5 \mathrm{~ms}^{-1}$ when exposed for $10 \mathrm{~min}$ or less to environments with large supercooled droplets [44]. Icing is a serious aviation hazard, and has been found to be a major cause in numerous air crashes [40], [45]-[47]. It has been estimated [48] that aircraft icing claims an average of 66 lives in 51 fatal accidents per year, most often involving general aviation or commuter-class aircraft. When icing conditions exist at ground level, ice coatings may form on runways, rendering them extremely slippery and causing aircraft to lose control during takeoff and landing.

PROCEEDINGS OF THE IEEE, VOL. 79, NO. 9, SEPTEMBER 1991 


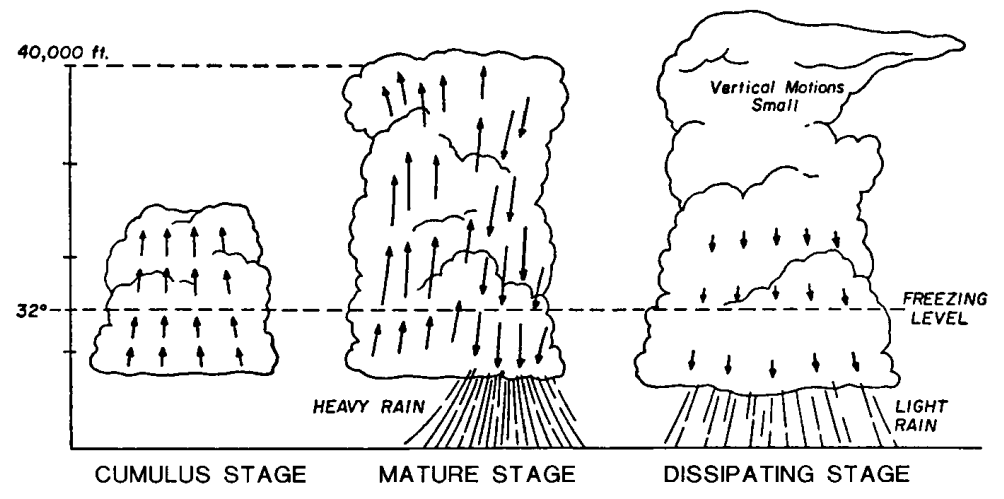

Fig. 3. The three stages in the life cycle of a thunderstorm. (Adapted from H. R. Byers and R. R.

Braham, Jr., The Thunderstorm, U.S. Government Printing Office, 1949.)

4) Low Visibility: As terminal area operations utilize a significant amount of visual inputs, a fair degree of visibility is necessary for this phase of flight operations. Poor visibility is caused by a number of phenomena. At somewhat higher altitudes (of the order of several hundred meters or more) a chief cause of poor visibility is a lowering of the cloud base, i.e., the bottom of cloud columns. At the ground level, a frequent visibility-reducing factor is fog, which is again a form of cloud activity. At all levels, visibility may suffer seriously due to precipitative phenomena such as rain [49], snow, and hail.

5) Electrical Phenomena: Atmospheric electrical phenomena in the form of lightning flashes are a matter of common occurrence and observation. Aircraft passing through regions of strongly charged clouds and strong electric fields may encounter [50], and indeed trigger [51], lightning. During a 1984 NASA Storm Hazards Program, an instrumented F-106B aircraft encountered 34 direct lightning strikes and observed lightning rates as high as 2.4 flashes per minute nearby (i.e., within the same radar resolution volume as the aircraft) while flying through storms [52]. Lightning may cause strong stray electrical currents through electrical and electronic circuits, resulting in malfunction and possible outage of onboard instruments and computers. It may also cause physical damage to the aircraft structure, and explosions due to the ignition of fuel-air mixtures [53].

\section{Origins of Hazardous Atmospheric Effects on Aircraft}

1) Thunderstorms: By far, the largest number of destructive atmospheric effects from the aviation point of view are associated with thunderstorms, as are a vast majority of weather-related aircraft accidents and incidents, and a significant fraction of delays. Out of eleven fatal weatherrelated air carrier accidents in the U.S. during 1962-1984, as many as nine occurred in the area of thunderstorms [11]. A compilation of the causes of 51 wind shear accidents or incidents between 1959 and 1983 shows that about twothirds of the events were associated with convective storms (thunderstorms and rain/snow showers) [54].
Thunderstorms [55], [56] are dynamic phenomena with well-defined life cycles that are initiated in environments where a deep unstable atmospheric layer exists from the ground upward. In such a layer, a rising parcel of air continues to rise under a force of positive (upward) buoyancy. The initial rise of the air parcel may be triggered by a relatively hot spot on the ground, mechanical lifting by sloping ground, or flow convergence at surface level, and this is followed by a continuing column of upward moving air forming a thunderstorm cell. In a highly unstable and deep layer of air, the buoyancy forces accelerate the rising air rapidly, which often attains vertical speeds of the order of $25 \mathrm{~ms}^{-1}(50 \mathrm{kt})$ at a height of $25000 \mathrm{ft},{ }^{1}$ though speeds two or three times this value are possible in the upper levels of a thunderstorm. The upward motion of air, called updraft, may continue up to altitudes over $40000 \mathrm{ft}$ or, in extreme cases, even over $65000 \mathrm{ft}$. These heights cover virtually all altitudes of interest to aviation. The unstable layer, in any case, cannot extend above the tropopause (bottom of the stratosphere) beyond which the atmosphere is very stable. When the rising air encounters a stable layer it decelerates rapidly, but may penetrate the layer by a few thousand feet because of its upward momentum. This first phase of thunderstorm growth, characterized by the presence of updraft throughout the cell, is called the cumulus stage (Fig. 3). The cooling of the rising column of air causes the moisture in it to condense, forming a tall column of cloud.

Following the cumulus stage the thunderstorm enters the mature stage, at the beginning of which the water droplets or ice particles in the cloud grow to a sufficient size to start falling down, and their drag causes a part of the air mass to descend. Evaporation of the falling water droplets or melting of the ice particles further cools the air, increasing its density and accelerating its descent. The mature thunderstorm therefore contains both rising and descending shafts of air at high speeds existing side by side.

${ }^{1}$ In aviation, heights are usually expressed in thousands of feet (kilofeet,
$\mathrm{kft}$ ) and such a unit is retained in this paper to describe atmospheric heights. 


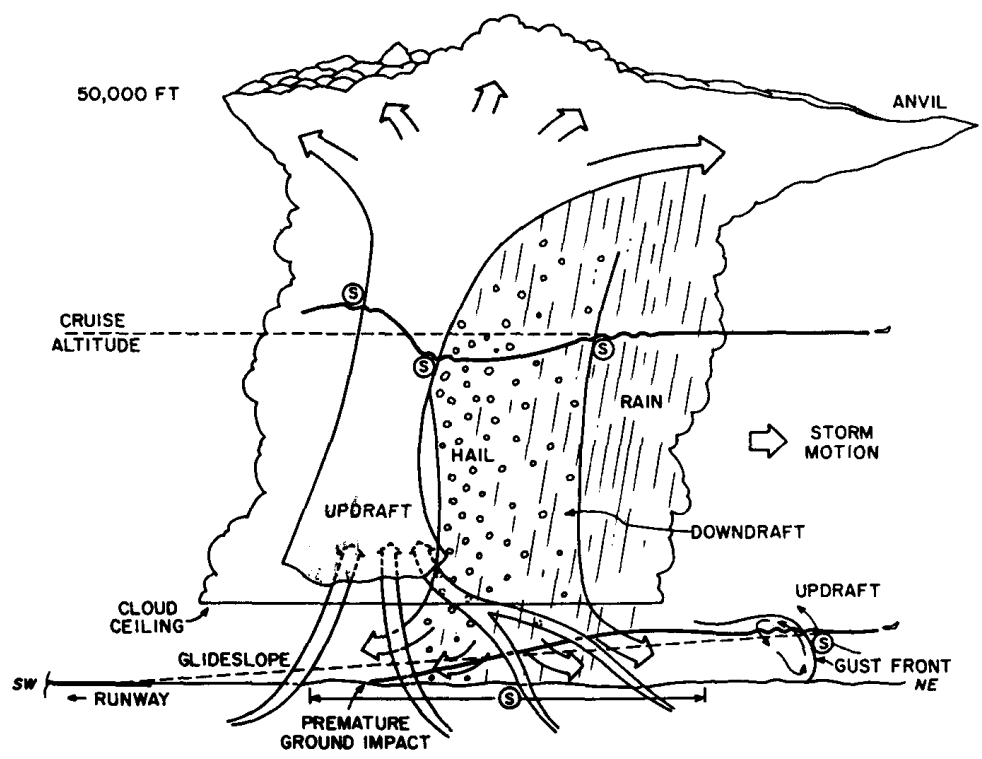

Fig. 4. The structure of a typical thunderstorm in the U.S. Midwest, and its effects on aircraft during cruise and landing. Dotted lines represent expected flight paths and solid lines are actual paths. The notation (S) indicates the likely zones of wind shear, and the wavy segments of flight paths are the result of turbulence. The updraft may have a superimposed rotation, resulting in helical air motion.

This is of particular significance to aviation, because an aircraft passing across the two columns will rapidly undergo a reversal of vertical air velocity, producing strong wind shear. There is also a high level of gustiness or turbulence within the storm. The falling water droplets constitute rain. Water drops may also freeze at high altitudes to form hail which may remain lifted by rising air currents for sufficient lengths of time to grow to sizes as large as several centimeters across, before they fall to the ground. The gust felt in the area of thunderstorms is caused by the descending cold air mass hitting the ground and spreading out laterally. Mature thunderstorms also exhibit a high level of electrical activity manifested as lightning flashes.

The final or the dissipating stage of the thunderstorm is reached when the upward momentum of air is exhausted and nearly all of the air mass in the storm is moving downward. This stage is characterized by relatively weak downdrafts throughout, and the turbulence, rain and lightning activity are diminished. The mass of cloud eventually evaporates.

A single thunderstorm cell is a few to several kilometers across, and has a life cycle of the order of an hour. It is a closed system in the sense that the storm air does not significantly interact with the ambient air to maintain a continuously ascending or descending flow. A class of severe thunderstorms, called supercells, are open systems believed to organize a steady flow to propagate through the ambient air, interacting with the large-scale environment of the storm. Supercells are found in environments characterized by strong low-level wind shear, rotation of the wind velocity vector with height, and sub- stantial convective instability [57]. These thunderstorms are of relatively infrequent occurrence, but are generally more violent than ordinary single-cell storms. Supercells have longer lifetimes (1-6 h), and often produce giant hail, strong surface winds, strong and persistent tornadoes, and intense updrafts $\left(25-50 \mathrm{~ms}^{-1}\right)$ that may coexist with strong downdrafts for relatively long periods of time [58]. A storm complex may contain several cells in different stages of evolution, giving it a larger spatial and temporal extent. Squall lines are lines of thunderstorms that may extend over hundreds of miles and often generate violent levels of rain, hail, and strong winds.

Although, in an evolutionary sense, a thunderstorm is a single entity, it is actually a highly complex phenomenon harboring/spawning several subphenomena and effects. The more significant of these are discussed here from the specific perspective of aviation. Figure 4 schematically illustrates the effects on the flight of an airplane at different levels through a thunderstorm.

Divergence is associated with thunderstorms at two altitude levels, and is capable of producing high magnitudes of wind shear. At higher altitudes, near the top of the storm, the rising air mass in the unstable layer spreads out radially when its vertical speed is arrested by the stable layer. Low altitude divergence results when the descending column of cold air encounters the ground. An aircraft entering a divergent flow field first encounters head wind, which turns rapidly into tail wind as the aircraft exits the field. This sudden reversal of wind results in a rapid loss of the aircraft's air speed and possible departure from its steady trajectory. Low altitude divergence produces a kind of wind 
shear that is particularly hazardous to aviation. The spatial scale of the wind reversal is typically a few kilometers, and aircraft attempting to land through such a field may experience the wind reversal in a time scale of the order of a minute. As aircraft about to land have low stall margins (usually about $30 \%$, i.e., the landing speed to stall speed ratio is about 1.3), such sudden loss of air speed induces $\mathrm{h} s^{-1}$ igh rates of descent (sink rates), which may lead to premature and steep ground impact (Fig. 4). The sink rate is further enhanced by the downward velocity component of the thunderstorm downdraft. Divergence-induced wind shear and the resulting high sink rate have been blamed for a large number of aircraft accidents in recent years [59]-[66]. Accidents can also occur during aircraft takeoff through a low altitude divergence because of a similar loss of aircraft speed (and hence altitude) [67], [68].

Downburst is a name given to a strong downdraft which induces a divergent outburst of damaging winds on or near the ground. A downburst with its outburst winds exceeding $4 \mathrm{~km}$ in horizontal dimension is called a macroburst, otherwise it is called a microburst. A macroburst can produce winds as high as $60 \mathrm{~ms}^{-1}$ (134 mph) lasting 5-30 min, and a microburst may induce winds up to 75 $\mathrm{ms}^{-1}$ (168 $\mathrm{mph}$ ) [69], the peak winds lasting only $2-5$ min. The microburst phenomenon has been implicated in many recent aircraft accidents/incidents [69], most notably the well-studied accidents at JFK (1975) [70]-[72], New Orleans (1982) [37], [73] and Dallas-Fort Worth (1985) [74] airports. Because of its smaller spatial dimension and shorter lifetime, a microburst is difficult to detect, and has attracted a high level of attention within the aviation safety community in recent years [6], [75]-[78]. A number of studies have been conducted to generate a knowledge base regarding microbursts. These include dedicated projects such as NIMROD [79], JAWS [80] as well as other studies (e.g., [81]). Microbursts do not always produce significant rain on the ground. When they do, they are called "wet microbursts;" otherwise they are "dry microbursts." In certain parts of the U.S. dry microbursts are more common. For example, in the Denver area, $83 \%$ of the JAWS microbursts were found to be dry, whereas in northern Illinois, $36 \%$ of the NIMROD microbursts were dry [82]. Wet microbursts such as the one causing the 1982 crash at New Orleans, and an Andrews AFB microburst a few minutes after the landing of Air Force One on August 1, 1983, can produce extremely heavy rain rates, exceeding $200 \mathrm{~mm} \cdot \mathrm{h}^{-1}$, over short periods of a few minutes [83]. Although wet microbursts are as deadly for aviation as the dry ones, the latter are somewhat more worrisome, as there is no significant visual clue to deter pilots from entering the area. The characteristics of microbursts in the U.S. are discussed in [84].

Cyclonic (rotational, about a near-vertical axis) motion of air is another significant source of wind shear. Mesocyclones are rotating masses of air with spatial scales of the order of $10 \mathrm{~km}$. The large scale shear produced by these phenomena is usually not of serious concern to aviation because of their relatively weak rates and large sizes, giving aircraft sufficient time to adjust and recover. Also, these phenomena are relatively persistent, providing adequate opportunity for their detection and warning. However, relatively strong and spatially small mesocyclonic features may excite the dynamical modes of aircraft. Further, thunderstorms associated with mesocyclones may locally cause hazardous levels of wind shear and turbulence.

Tornadoes are very violent cyclonic phenomena spawned by thunderstorms. The average diameter of tornadoes is about $100 \mathrm{~m}$ [85], with the vast majority being less than $1.5 \mathrm{~km}$ and many less than $30 \mathrm{~m}$ [55]. Maximum wind speeds in the most intense tornadoes have been estimated to lie in the range $110-125 \mathrm{~ms}^{-1}(250-275 \mathrm{mph})$ [85], [86]. Such very high speeds occurring within a small spatial extent cause tremendous wind shear which gives tornadoes devastating destructive power capable of physically destroying aircraft on encounter. The situation is further complicated by the fact that tornadoes form rapidly and move in apparently random directions, making their prediction difficult. Fortunately, because of their small size, short life, and geographical distribution in the U.S. [87], their probability of encounter with aircraft in flight is very small. Also, tornadoes are very often produced by severe thunderstorms which are normally avoided by pilots, though many smaller tornadoes are associated with nonsupercell storms. These reasons explain the near-absence of air disasters directly caused by tornadoes. However, tornadoes have caused damage to aircraft parked on the ground and have been suspected in some unexplained accidents (e.g., a 1981 crash in Holland in which a wing of the aircraft broke off during low-level flight).

A gust front is the leading edge of the divergent horizontal air flow resulting from the thunderstorm downdraft being deflected by the ground. It forms the interface between warm, moist air close to the ground in the thunderstorm environment, and the cool, nearly saturated air originating from the middle of the thunderstorm. Gust fronts, characterized by spatial scales of $10-50 \mathrm{~km}$ [88], can harbor horizontal winds with speeds exceeding $25 \mathrm{~ms}^{-1}(55 \mathrm{mph})$ behind the front [89]. The sudden wind change (shear) experienced by an aircraft when it flies through the gust front, together with the very high level of turbulence usually encountered behind the front, makes the gust front a very dangerous phenomenon associated with thunderstorms. Although the gust front exists in the thunderstorm environment, the front itself often occurs in clear air (i.e., without much precipitation) and is not visually detectable except for the dust and debris it may raise. (Gust fronts may be accompanied by characteristic cloud patterns, but these are not reliable indicators of the severity of the front.) This fact increases the aviation hazard potential of the gust front. A further complicating factor is that gust fronts can propagate tens of kilometers from their parent storms while retaining strong enough wind shear and turbulence to seriously affect flight. Their presence, therefore, cannot always be inferred merely by association with the parent storm.

Rain and hail are the most visible products of a thunderstorm. In a mature thunderstorm, heavy sustained (5-10 min 
average) rain rates exceeding $25 \mathrm{~mm} \cdot \mathrm{h}^{-1}$ at the ground level are common and those exceeding $100 \mathrm{~mm} \cdot \mathrm{h}^{-1}$ sometimes occur [90]. Instantaneous rain rates (over 1 $\min$ ) appear to be much higher; values of 1000 and 1900 $\mathrm{mm} \cdot \mathrm{h}^{-1}$ have been suspected in certain thunderstorms in the U.S. Because a part of the rain evaporates during its fall or maybe imbedded in downdrafts, local rainfall rates at certain altitudes within thunderstorms are often different than those observed on the ground. This fact is important because instruments such as radars can detect the precipitation aloft even when there is no precipitation at ground level. Hail stones occur in various sizes in thunderstorms. Hail sizes up to a few or even several centimeters diameter are possible, though the probability of occurrence of the larger sizes is lower. Hail has been encountered at heights as much as $45000 \mathrm{ft}$ [91] and is thus a hazardous factor to flight at all levels. Rain and hail activity varies considerably over different areas of the thunderstorm and may be significantly different at flight altitudes from those observed on the ground at any given time.

Icing over aircraft surfaces occurs during flight through thunderstorm clouds at heights near the freezing altitude level. Normally the flight time of aircraft through single thunderstorm cells is too short to cause dangerous levels of icing, but it is possible for the ice accumulation rate to be high enough to affect flight seriously, especially when there is a high concentration of supercooled liquid water, and relatively long dwell periods are involved, such as in flying through widespread precipitation. In cold weather conditions, when icing conditions extend down to ground level, aircraft exposed to it over long periods during parking, taxiing and takeoff may acquire a dangerous buildup of ice [92].

Snowstorms occur when deep layers of frigid air exist from ground upward. Heavy snowfall rates create problems in runway operation, and are a chief cause of poor visibility. Other contributors to poor visibility in air terminal areas are heavy rain, low-base/precipitating clouds, fog, and dust storms.

Although the preceding paragraphs discuss thunderstorm effects individually, the picture in the area of a storm is quite complicated, with many of these effects acting simultaneously on aircraft. For example, aircraft attempting to take off or land through a thunderstorm may experience icing, wind shear due to low-level divergence, severe turbulence due to the gustiness of the descending/ascending air mass, heavy rain and hail, and poor visibility, all at the same time (e.g., [40]). The combined effect of several factors is usually more detrimental than isolated factors. For this reason, the detection, characterization and hazard potential estimation of thunderstorms and their related phenomena form the prime focus of the electronic systems designed for the enhancement of aviation safety.

2) Other Sources of Atmospheric Hazards to Aviation: Several sources not directly connected with thunderstorms can produce atmospheric effects that influence aviation adversely. Low level or nocturnal jets are a source of wind shear

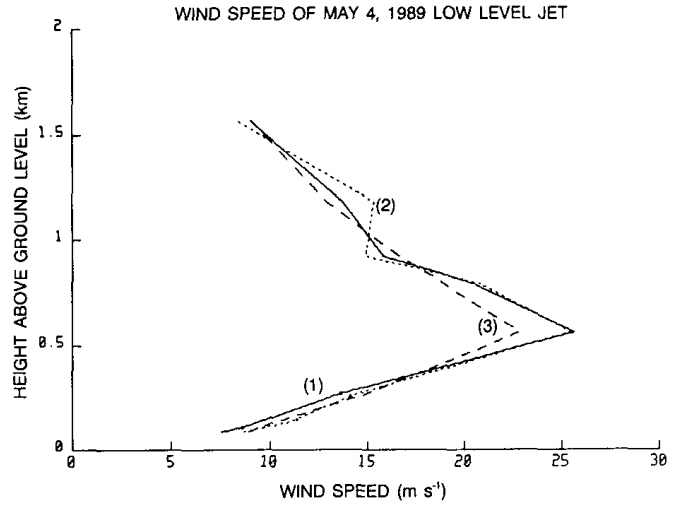

(a)

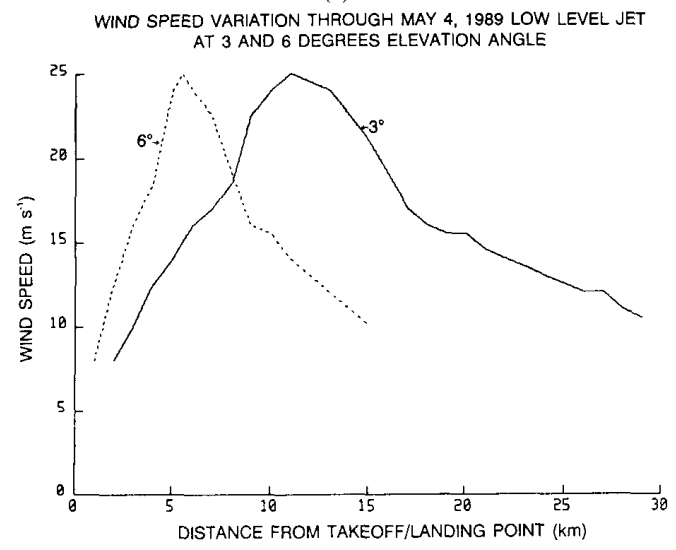

(b)

Fig. 5. Wind speed profiles due to a low level jet observed on May 4, 1989 in the vicinity of the Kansas City International Airport during the FAA evaluation of the Terminal Doppler Weather Rada System. The vertical profile (a) shows a sharp peak at about 500 $\mathrm{m}(1500 \mathrm{ft})$ altitude, with strong wind shear above and below this height. An aircraft attempting to take off (at a $6^{\circ}$ angle) or land (along a $3^{\circ}$ glideslope) through the jet would experience the wind variations shown in (b). (Courtesy of Sonia G. Lasher.)

that produce winds in the range of $10-30 \mathrm{~ms}^{-1}(22-66$ $\mathrm{mph}$ ) at a height of about $600 \mathrm{ft}$ above ground while surface winds may be calm [93], [94]. The wind profiles in Fig. 5 illustrate the nature of wind shear hazard posed by low level jets. Fronts or interfaces between cold and warm air masses are also the cause of considerable wind shear. Similarly, significant wind shear may be caused by the land breeze and sea breeze phenomena in areas close to the sea. Finally, topographic factors are capable of inducing considerably strong wind shear, which is more significant for takeoff than landing, due to limitations imposed by operational requirements [95]. Included in this class are mountain waves, which have been suspected in certain air crashes. Propagating waves and bores, which may arise from thunderstorms but may propagate hundreds of kilometers under suitable conditions of the atmospheric boundary layer, can also produce transient or periodic wind shifts of sufficient intensity to be hazardous to aircraft [96]-[98].

PROCEEDINGS OF THE IEEE, VOL. 79, NO, 9, SEPTEMBER 1991 
Of concern to aircraft safety and airport efficiency, are the wind shear and turbulence caused by wing-tip vortices. Aircraft generate their lift force essentially by creating a pressure differential between the upper and lower surfaces of the wings. Air flowing around wing tips from the lower side (where the pressure is higher) to the upper causes vortices, which spread out conically behind the tips, affecting closely following aircraft. The vortices are stronger for aircraft with higher wing loading, such as supersonic aircraft. The strength of aircraft-induced wake vortex, and the length of the vortex zone, are higher for larger and heavier aircraft (which have to generate more lift), and are among the factors that determine the minimum spacing between aircraft in the landing queue at individual runways. Although the length of the vortex caused by each type of aircraft in still air is predictable, in practice considerable variability of the tip vortex length along the runway occurs due to the wake being blown off the runway by cross winds. Being able to observe the vortex lengths will permit the aircraft spacing to be closer than following the "worst case" rule, and thus will increase the traffic handling capability of individual runways. Although wake shear is not a weather-related phenomenon, it is mentioned here because its detection could be based on techniques and sensors similar to those used for weather-related wind shear. Airborne detection of wake vortices is a field of joint study by the Federal Aviation Administration (FAA) and the National Aeronautics and Space Administration (NASA) [99].

\section{REQUiREMENTS OF SENSORS AND SyStems For Aviation Weather SuRVEILlance}

The requirements of aviation weather monitoring systems must be discussed from temporal and spatial aspects. The time update rates (or agility) of information from such systems is decided primarily by the time scales over which aviation-significant phenomena build up, decay or change significantly. As a general rule, phenomena of larger spatial scales are also temporally more stable, providing more time for their detection. Even the general activity level of thunderstorms (e.g., updraft, rain, lightning frequency, etc.) has a characteristic time scale of the order of several tens of minutes [100]. However, individual phenomena associated with thunderstorms often build up and decay much more rapidly. Perhaps the most stringent requirements in terms of detection system agility is imposed by microbursts. Analysis of data from CLAWS and JAWS projects [101] has shown that in a group of 27 microbursts, after lowaltitude divergence was first observed by radar, the outflow reached microburst intensity in $2.5 \mathrm{~min}$ on an average, and the maximum outflow intensity (wind shear) was reached 5 min thereafter. The microbursts also decayed rather fast, on an average about $8 \mathrm{~min}$ after the maximum shear, giving a total average lifetime of about $13 \mathrm{~min}$. To minimize false alarms, flight management procedures usually require an observation to be confirmed in at least two consecutive observation cycles before warnings are issued. Thus the data update intervals of observation systems should be at least a half of the growth and decay periods of hazardous phenomena, allowing time for processing, communication, display and interpretation. Considering the $2.5 \mathrm{~min}$ average buildup time of the outflow to reach microburst intensity (many microbursts would build up faster than this average value) such a criterion sets a limit of about one minute on the data update interval of surveillance systems for microburst detection. Even with such a data rate, the time available for interpretation and communication of data is very small, which would necessitate these functions to be carried out by automatic means. It is accepted by the FAA that the hazard to aircraft due to low-altitude wind shear (such as that produced by microbursts) can only be addressed by a fully automatic detection and warning system [102].

The spatial aspects of aviation weather surveillance include both coverage as well as resolution. The spatial coverage of the system should include all the designated flight corridors within the airspace, as well as the space above terminal areas. It should also cover areas of commercial, general, as well as military aviation activities. In terms of resolution, the observation requirements in terminal areas is more stringent than those outside, because air traffic is dense within terminal areas, and the aircraft in landing and takeoff stages are more vulnerable to hazardous weather factors. Three zones have been specified by the FAA [103] in relation to weather surveillance by radars (Fig. 6): the airport area which covers a radius of $20 \mathrm{~km}(12 \mathrm{mi})$ from the center of the runway complex, the terminal area covering a radius up to $56 \mathrm{~km}(36 \mathrm{mi})$, and the en route area which is outside the terminal area.

Hazardous levels of atmospheric air motion usually occur in an environment of precipitation, in which case air motion is readily detectable by radars. However, requirements for aviation weather surveillance also include detection of hazardous air motion in clear air, which is associated with phenomena such as gust fronts and dry microbursts. This requirement is again more important in terminal areas than en route.

The surveillance of aviation weather not only involves the observation of the atmosphere with sensors, but the processing and interpretation of the data to assess its hazard potential, communication of the products of the processing to the control towers and aircraft, and presentation of the products to controllers and pilots to aid them in decisions regarding flight. A highly simplified schematic of the information chain is shown in Fig. 7. To minimize interference with (and the work load on) the already complex and burdened ATC system, the weather information system should be nonintrusive and autonomous as far as possible. The goal of a modern aviation weather system is, therefore, to be able to process data and draw inferences by automatic means and communicate them to pilots of aircraft, with minimal (preferably optional) interference from ATC or meteorological personnel. As pointed out before, such automatic processing also reduces the delay between the observation of a fast-growing hazardous phenomenon and 


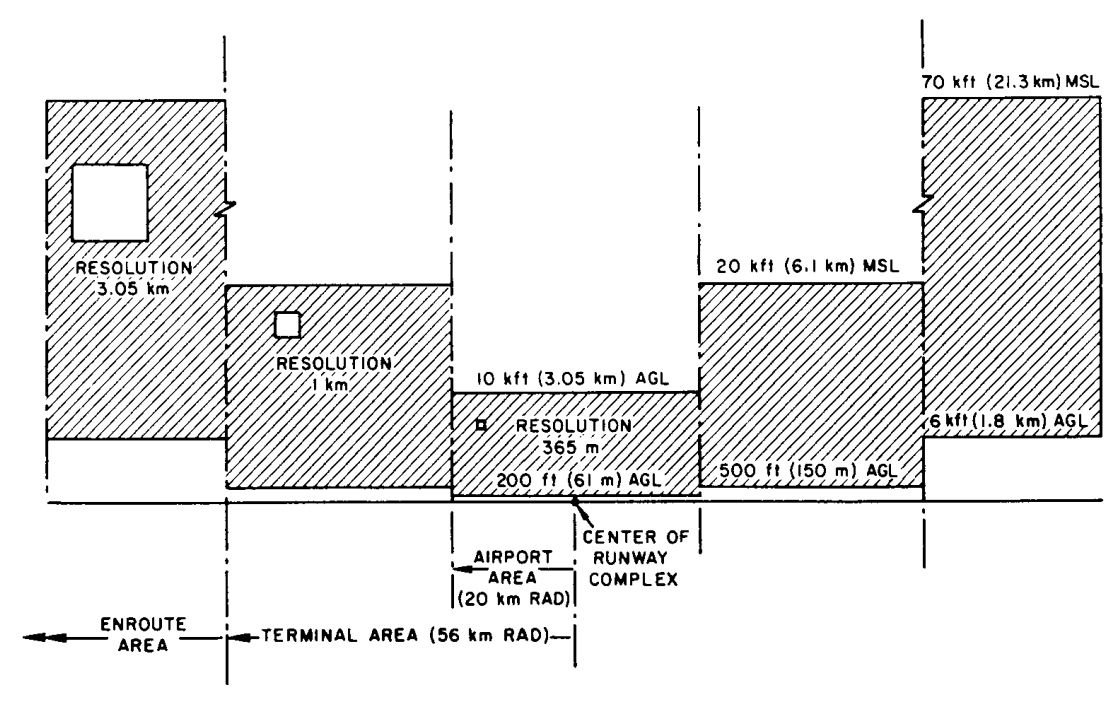

Fig. 6. The FAA requirements for weather radar coverage (maximum and minimum heights of observation) and resolution in different flight areas.

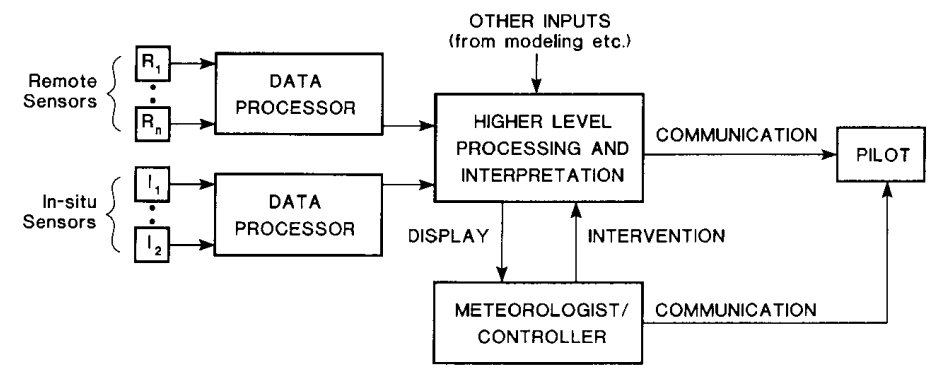

Fig. 7. Simplified schematic of the information chain in a modern aviation weather system.

its communication to the pilot to help him make the appropriate decisions.

The final element in the aviation weather information chain is the display that conveys the processed information to the pilot and the air traffic controller. This is a crucial element, because it involves the conveying of a vast amount of information in the shortest possible time, about a complex, multiparameter situation to human operators who are performing a variety of other high-priority tasks simultaneously. The science, engineering and implementation of such display devices, formats, and software is also an active area of current research and development.

\section{The Doppler Weather Radar As A Primary AVIATION WEATHER SENSOR}

For a complete picture of the weather scenario relevant to aviation, information must obviously come from multiple sources. However, because of a matching of coverage requirements, resolution and data update rate, radar has emerged as the primary sensor for aviation weather surveillance. Radars can detect weather phenomena out to hundreds of kilometers in range and provide detailed threedimensional pictures of weather fields. A modern weather radar provides multiple parameters of the phenomena being observed, which permits more accurate interpretation and hazard potential estimation of the phenomena.

Conventional weather radars, such as the currently operational WSR-57, provide a picture of the echo intensities over an area that is more than $400 \mathrm{~km}$ in radius, with an effective range resolution of the order of a kilometer. During the past decades these radars have been very helpful in general weather surveillance, but from the aviation perspective, they have a number of limitations: 1) The echo intensities only roughly correspond to actual precipitation intensities. Quantitative rainfall rates, especially local values, are often in error by significant factors. 2) As only one parameter, i.e., the echo intensity, is available for inferring the nature of precipitation (rain or hail), either hail detection may be missed or excessive false alarms may result, depending on the threshold used to infer hail. 3) 
Because of their relatively broad beam (width about $2^{\circ}$ ), the observation is blurred far away from the radar. 4) Only the precipitation field around the radar is mapped. There is no explicit data about the motion of air masses, which is of prime importance to aviation.

To overcome the last deficiency, modern weather radars employ the Doppler principle. By coherently processing the echo signals from weather phenomena, parameters related to the motion of air can be obtained, which can be utilized to characterize the motion and estimate its hazard potential. Doppler radars have been used for military applications for a long time and their technology has been perfected to a great extent in that context. The use of Doppler radars for atmospheric studies is, however, relatively recent. Research Doppler radars were designed and operated during the 1970 's, and it is only during the 1980's that Doppler weather radars for operational applications have been developed. Aspects of generic and specific Doppler weather radar systems relevant to aviation are discussed in the following sections.

\section{A. The Doppler Weather Radar and Its Data Products}

Radars usually transmit electromagnetic energy and depend on the reception of a tiny fraction of the energy scattered by objects or "targets" to detect and characterize the targets. In the case of weather phenomena, the scattering effect is most commonly produced by the ensemble of hydrometeors such as rain, snow, or hail. Rain drops, because of their small size (high drag/mass ratio), quite faithfully follow the local horizontal air motion; in a vertical direction their velocity is a superposition of their terminal fall speeds in static air, and the vertical components of the local wind speeds. Rain drops therefore act as "tracers" for the air motion, and Doppler radars measure the motion parameters of these tracers to draw inference about atmospheric air motion.

The theory of Doppler weather radars is treated in detail in [104] and [105]. Only certain aspects relevant to the understanding of weather radar data products are outlined here. The basic schematic of a radar beam illuminating a number of scatterers in a resolution volume is shown in Fig. 8. Each particle in the resolution volume produces an echo which appears at the receiver as a complex quantity. As the individual particles within a resolution volume cannot be resolved from one another, the instantaneous signal sensed by the receiver is the sum of the echo returns from all the particles within the volume. (In practice, the particles are not uniformly "illuminated," hence the sum is actually weighted by the shape of the transmitted pulse in the range direction and by the antenna pattern in the cross-range directions.) Successive samples of the return from a given resolution volume form a complex time series, which can be processed coherently to generate the desired data products.

The generation of data products by a Doppler weather radar maybe better understood by switching over to the spectral domain. A (discrete) Fourier transform of the time series received from a resolution volume would represent the frequency spectrum of the Doppler returns from the

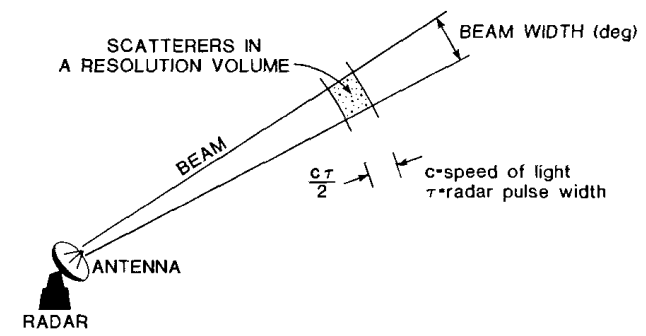

Fig. 8. The basic geometry and some basic parameters of weather radar.

ensemble of scatterers within the volume (Fig. 9). If the particles are static relative to one another and to the radar (a hypothetical case), the spectrum of the returns would resemble that from a single target, as in Fig. 9(a) and (b). However, in practice, the particles move relative to one another and to the radar. Each moving scatterer produces a different Doppler shift, causing the received signal spectrum to broaden, as in Fig. 9(c). In addition to the broadened spectrum envelope due to atmospheric scatterers, the signal spectrum would also usually contain components due to ground clutter, located at or close to the zero-frequency line. The complete spectrum is shown schematically in Fig 9 (d).

In Fig. 9(e) the weather signal spectrum alone is magnified, showing its basic parameters. Most commonly, three moments of the spectrum are of interest in weather surveillance. The zeroth moment, which is the area under the spectrum curve, represents the total echo power received from the scatterers in the resolution volume. After normalizing with respect to the radar carrier frequency, range, and the volume of the resolution volume, the echo power intensity is given in terms of a "reflectivity factor" (symbol: $Z$ ), which is often written simply as "reflectivity" and is usually expressed in decibels (dBZ). The reflectivity factor (unit: $\mathrm{mm}^{6} / \mathrm{m}^{3}$ ) of a population of small (relative to the radar wavelength) hydrometeors is proportional to the sum of the sixth powers of the diameters (in $\mathrm{mm}$ ) of the particles in a unit volume $\left(1 \mathrm{~m}^{3}\right)$ of space [105]. To form an idea of the actual numbers involved, rainfall showing $50 \mathrm{dBZ}$ of reflectivity corresponds to a rain rate of the order of 50 $\mathrm{mm} \cdot \mathrm{h}^{-1}$ and the heaviest rain events, usually containing hail, produce about $65 \mathrm{dBZ}$ of reflectivity. The highly nonlinear (sixth power) dependence of the reflected power on particle size, which arises from the physics of Rayleigh scattering, causes rapid improvement in detectability and parameter estimation accuracy with increase in particle size, which usually occurs with higher precipitation rates. For this reason, water droplets of the sizes found in clouds are almost invisible to weather radars, which usually operate at a wavelength of several centimeters. Reflectivity serves as a fair indicator of the level of precipitation activity, though considerable errors may exist in estimating instantaneous local rainfall rates from reflectivities alone. 


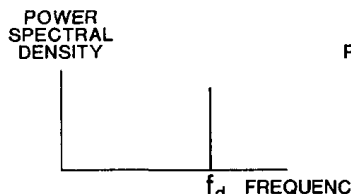

(a)

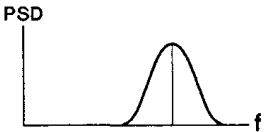

(c)

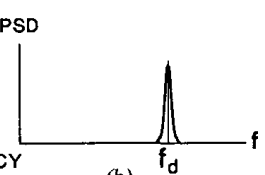

(b)

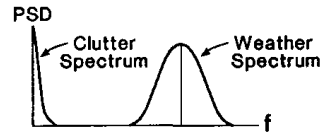

(d)

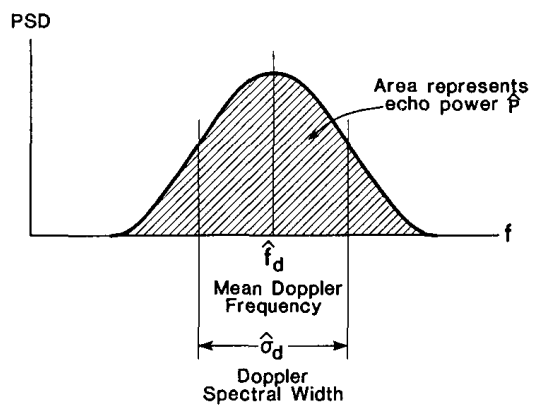

(e)

Fig. 9. Radar echo signal representation in the spectral domain: (a) ideal return from a point target moving relative to the radar, (b) actual signal from a point target having finite spectral width due to antenna rotation and other real effects, (c) ideal return from weather targets, (d) composite spectrum due to clutter and weather, and (e) magnified view of weather spectrum alone, showing the three major parameters.

Reflectivity is the only radar parameter directly measurable by conventional weather radars such as the WSR-57 and the WSR-74, and has been in use over the past decades for weather monitoring for many purposes, including aviation warnings. The relatively large size of hail produces very high reflectivities due to the $D^{6}$ dependence. However, it is difficult to distinguish rain, hail, and rain/hail mixtures from one another based on reflectivity alone, because there is a considerable overlap between the reflectivities of hail and heavy rain. In tropical and subtropical regions, rain storms without hail commonly produce reflectivities of 60 $\mathrm{dBZ}$ or more, while at higher latitudes, storms exceeding $55 \mathrm{dBZ}$ in reflectivity may be expected to contain hail of 19 $\mathrm{mm}(3 / 4 \mathrm{in})$ in diameter or more, which are hazardous for aircraft. As a common criterion, storms with reflectivities over $55 \mathrm{dBZ}$ should be considered as having a high level of precipitation hazard potential (rain or hail) and therefore to be avoided by aircraft. As will be pointed out later, modern weather radars (which happen to be Doppler) have a high accuracy of reflectivity measurement, usually of the order of $1 \mathrm{~dB}$, which will make the reflectivity thresholding reliable.

The mean Doppler frequency of the spectrum in Fig. 9(e), which can be derived from the first moment of the spectrum, corresponds to the mean radial motion of the scatterers relative to the radar. This parameter gives the radial component (relative to the radar) of the mean wind over the resolution volume. Radial wind measurement is a very important Doppler weather radar function, and its implications are discussed in the following paragraphs. The width of the Doppler spectrum in Fig. 9(e), which can be derived from the second moment of the spectrum, is a measure of the relative motion of the scattering particles within the resolution volume. Differential scatterer motion may arise from random air motion or turbulence, or the more systematic differential air motion such as wind shear occurring within the resolution volume. Although the Doppler spectrum width of the echo signals from individual resolution volumes is a result of both these effects, it is possible to separate these two effects to a certain extent using data from a larger volume of the atmosphere containing the particular resolution volume [106]. However, except in areas of strong wind shear, which are usually only a small fraction of the total volume under surveillance, the Doppler spectrum may be used as an indicator of the turbulence level. This is confirmed by experiments which show a very high level of correlation $(90 \%-95 \%)$ between radar-measured Doppler spectrum widths and actual aircraft-measured turbulence levels [107]-[109]. The agreement is almost complete at higher turbulence levels, which are of concern in aviation safety. As far as aviation is concerned, wind shear and turbulence are both hazardous to flight (though in different ways); thus it is not considered necessary to accept the extra computational burden of separating the wind shear from turbulence within individual resolution volumes. Instead, the Doppler spectrum width itself can be used as the basis for aviation hazard warning. It is reasonable to associate a spectrum width threshold of $4 \mathrm{~ms}^{-1}$ with uncomfortable flights and $6 \mathrm{~ms}^{-1}$ with potential hazard [107]. However, these figures have not yet been established rigorously. More research is required to determine the detection and false alarm behavior of these thresholds.

The reflectivity, mean Doppler velocity, and Doppler spectral width are the primary products of a Doppler weather radar. The basic block diagram of a radar generating these products is shown in Fig. 10. Individual Doppler radars may vary in some detail from this diagram, but the broad features are common to most systems. Several methods are possible both in the time and the spectral domains to derive the Doppler spectral moments from the complex time series of the radar returns. However, as the estimation of spectral moments is a highly repetitive process, being required to be performed for each range location along each distinct radial (spaced about one beam width intervals), the estimation algorithms must be kept as simple as possible to be implementable in real time. A very common algorithm used for spectral moment estimation is based on the pulsepair method [110]-[112]. The "raw" moments, as obtained from the estimator, are usually subjected to "clean up" operations before utilization in further processing. These operations include dealiasing to remove range and velocity ambiguity effects [113]-[115].

Primary Doppler radar weather products are normally displayed on plan position indicators (PPI's), or, less 


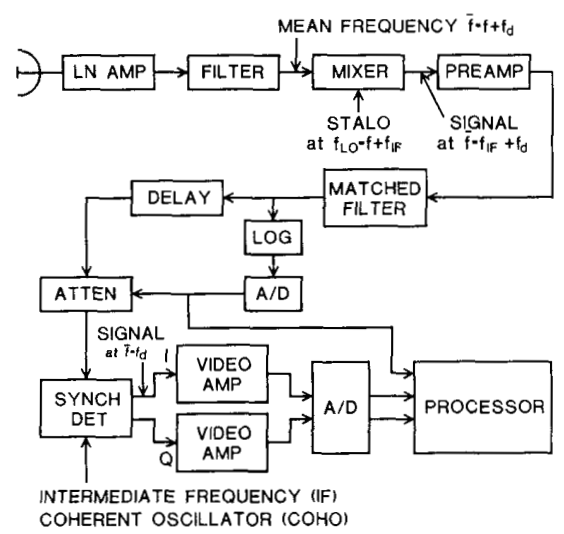

Fig. 10. Simplified block diagram of a modern Doppler weather radar.

frequently, on range-height indicator (RHI) displays. Each type of air motion, such as steady wind fields, and fields associated with mesocyclones, tornadoes, convergent/divergent flows, gust fronts, etc., has a distinct signature on the primary displays, from which experienced interpreters can determine many qualitative and quantitative aspects of the phenomena. An even better visualization and parameter estimation of air motion fields may be achieved by observing the field with two spatially separated Doppler radars (the so-called dual-Doppler arrangement) which provide the velocity components at each point in the field along two different directions. Using these projections it is possible to construct the true (or vector) horizontal velocity fields [116], and even the vertical velocity components through the differential equation of continuity [117].

Although the art of feature recognition and parameterestimation from the primary radar product displays by experienced human observers is highly developed, such a method is not considered to be very effective and efficient in the aviation context. Apart from requiring substantial personnel resources, such a man-in-the-loop approach to aviation hazard warning introduces delays into the warning process which are considered unacceptable in the dynamic environment of aviation operations. For this reason, modern Doppler radars designed for aviation weather surveillance aim to perform most of the feature detection, recognition, severity/hazard estimation, and tracking/prediction functions by automatic means [118]. Among the first family of automatic algorithms to be evolved were those for the identification and tracking of storm cells. Three different approaches have been used for developing storm cell algorithms: 1) centroid tracking [119], 2) correlation tracking [120], [121] (this method has also been used for tracking clear-air features and recovery of winds from single radar observations [122]), and 3) peak-cell tracking [123]. The first was implemented in real time at the Air Force Geophysics Laboratory (AFGL) in the late seventies [124]. More recently, algorithms have been developed for the automatic detection of mesocyclones
[125], divergence [126], [127], microbursts [128] and gust fronts [129], [130]. There is an increasing trend toward using artificial intelligence techniques in the recognition process (e.g., [131]-[133]). A sample output of one of these algorithms is shown later in this paper. As a dual-Doppler radar arrangement is not considered cost-effective in most operational situations, these algorithms usually utilize the radial velocity data of a single Doppler radar as input. The automatically sensed features of weather phenomena, utilizing the primary data products of Doppier radars, are called the higher level data products of the surveillance system. The generation and display of higher level products is a significant aspect of the currently developing weather radars for aviation.

\section{B. The Modern Doppler Weather Radars for Aviation}

The emphasis of aviation safety planners on radar-based weather surveillance and nowcasting may be judged from the fact that currently as many as three operational Doppler weather radar systems are under parallel development, of which two are wholly dedicated to aviation and the third is designed to play a major role in aviation. The two dedicated systems are the Terminal Doppler Weather Radar (TDWR) and the latest Airport Surveillance Radar (ASR-9) which has a dedicated weather channel. The third system is the Next Generation Weather Radar System (NEXRAD).

1) The Next Generation Weather Radar: The NEXRAD project is the first of the three Doppler weather radar project, to be initiated. Code named WSR-88D, and beginning to be deployed across the U.S., it was started in the late 1970's as a triagency project involving the Departments of Commerce, Transportation and Defense. As such, it is designed for supporting multiple nowcasting functions, with important potential contribution to aviation [134]. Prominent in this connection is WSR-88D's projected role as an accurate and reliable system to supply data on en route storm conditions and potentially dangerous local turbulence without adding to the already heavy work load of air traffic controllers [135]. It is also expected to cater to the needs of military and general aviation aircraft.

The WSR-88D system, is designed to significantly enhance tornado warnings, improve the detection and measurement of damaging winds, severe turbulence, wind shear, and hail storms, and more accurately delineate areas that are threatened by severe weather [135]. It is also expected to substantially reduce the number of false alarms and incorrect forecasts of severe weather, and improve the display and dissemination of radar data products.

The WSR-88D is a fully coherent radar operating in the $10-\mathrm{cm}$ band with a pencil beam of width somewhat less than $1^{\circ}$. The main parameters of the WSR-88D system are given in Table 2 [135], [136]. The major units of the system are (Fig. 11) the Radar Data Acquisition (RDA) unit, the Radar Product Generator (RPG) and the Principal User Processor (PUP). The first unit performs the basic radar functions such as the transmission, reception and processing of signals, the second performs the computational functions for generating the radar data products, and the last unit 


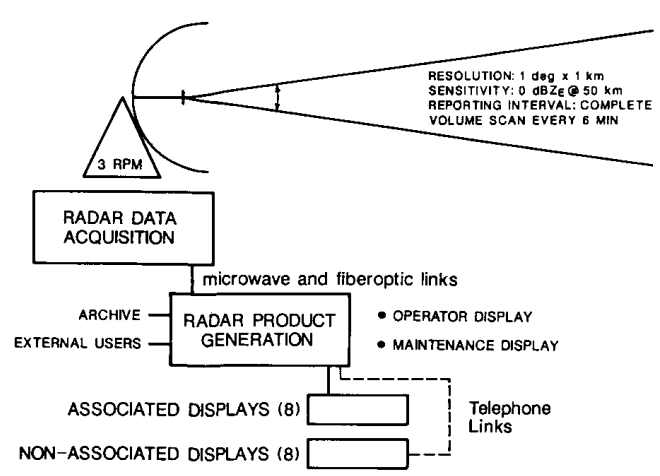

Fig. 11. The relationship between the major subsystems of the NEXRAD.

maintains interface with users and provides display and control of data at user locations. The WSR-88D uses highquality full-color displays for primary data products and has powerful software for generating higher level weather products, which include precipitation accumulation, identification and parameterization of storms, mesocyclones, divergence, tornadic vortices, turbulence zones and wind shear zones. Figure 12 is a sample of WSR-88D primary data displays.

The WSR-88D has a very high dynamic range (95 dB) to facilitate weather observation over long ranges, and in clear air as well as precipitation environments. It also has high sensitivity $(-8 \mathrm{dBZ}$ at $50 \mathrm{~km})$, and a high level of clutter rejection capability ( $54 \mathrm{~dB}$ for fixed targets), for which it utilizes five-pole digital IIR filters having softwarecontrolled notch widths [136]. Operationally, the radar is capable of remote, unattended operation and transmission of the raw products to the RPG. It has two operational modes currently defined: precipitation and clear-air modes. Three scan strategies have been specified, which may later be extended to as many as eight. Special techniques have been adopted to achieve a very "clean" spectrum of the transmitted signal to satisfy radio-interference constraints. A highly developed self-calibration scheme is incorporated to achieve the desired levels of measurement accuracy.

During a period of operational test and evaluation completed in August 1989, the WSR-88D system has demonstrated a probability of detection of $91 \%$ and false alarm rate of $21 \%$ for severe thunderstorms, which are major improvements over the national averages of $58 \%$ and $57 \%$ as the corresponding figures for the current weather radars [136]. The procurement process has begun for the eventual deployment of about 150 of these systems across the continental U.S. Including the outlying areas and some overseas locations, the eventual number may be somewhat higher. Most parts of the continental U.S., including coastal sea zones, will have WSR-88D coverage (Fig. 13), with about $70 \%$ of the landmass being covered by more than one such system (considering a $235 \mathrm{~km}$ radius of coverage of each system). It has been shown [137] that a WSR-
88D positioned about $10-12 \mathrm{~km}$ from an airport runway complex can very nearly satisfy the FAA requirement on terminal area weather surveillance. A radar location 10-30 $\mathrm{km}$ away from the runway area has also been suggested for early detection of microbursts [83].

However, because such stringent siting requirements, and the necessary scanning agility for terminal area surveillance, would severely constrain the overall planning of the WSR-88D chain and its other observational requirements, WSR-88D's have been designated essentially for weather monitoring in en route airspaces. Also, the WSR-88D scan cycle is considered too slow for terminal area surveillance, but is adequate for enroute weather data which has only a 10-min update requirement [10]. However, with proper siting relative to airports, and proper choice of scan cycles and signal processing schemes, WSR-88D's could perform a large part of terminal area weather surveillance functions, and provide backup for dedicated airport weather radars. The en route surveillance capability of the WSR- $88 \mathrm{D}$ is unique among the three Doppler radars. The other two Doppler radar systems, namely the TDWR and the ASR-9, are essentially for terminal area aviation operations only.

2) The Terminal Doppler Weather Radar: In addition to the network of WSR-88Ds, a need has been felt in the aviation community for closer and more dedicated surveillance of aviation-significant weather, especially wind shear in terminal areas. This is because wind shear effects during landing and takeoff have accounted for a major fraction of weather related aircraft accidents. The TDWR program is in response to this need.

The Development of the TDWR was strongly motivated by the requirement of timely and reliable detection of microbursts [138]. Its other primary functions are the detection of gust fronts and the prediction of gust-frontal wind shifts, as well as the estimation and graphic display of precipitation over terminal areas. Yet other aims of the TDWR are to predict storm movements, estimate turbulence in precipitation areas, detect tornadoes, and predict the surface impact of microbursts and the initiation of convection leading to the formation of thunderstorm cells. The location of the TDWR within the airport area would enable it to effectively observe microburst outflows which have depths between 300 and $1200 \mathrm{~m}$ [101], with the strongest winds in the lowest 100 $\mathrm{m}$ [139]. To facilitate the measurement of wind shear at the lowest altitudes, good ground clutter suppression is a primary design feature of the TDWR [140]. Further, in its 5 -min scan cycles, the lowest level of scan is visited once every minute, to conform with the microburst detection criterion established in Section III.

Some of the basic parameters of the TDWR system are listed in Table 3 [140], [141]. A major difference of the TDWR with respect to the WSR-88D is its operating wavelength of about $5 \mathrm{~cm}$, against $10 \mathrm{~cm}$ for the WSR$88 \mathrm{D}$. The decision regarding the operating frequency of the TDWR has resulted from the lack of spectrum allocation at S-band [140], [142]. The 5-cm wavelength has the advantages (compared to $10 \mathrm{~cm}$ ) of lower radio frequency interference, and better signal-to-clutter ratio from equiva- 
Table 2 NEXRAD Characteristics

\begin{tabular}{|c|c|}
\hline Parameter/Feature & $\begin{array}{ll} & \text { Value/Description } \\
\end{array}$ \\
\hline Radar range & Reflectivity: $460 \mathrm{~km} \quad$ Velocity: $230 \mathrm{~km}$ \\
\hline Elevation coverage & Operational: $-1^{\circ}$ to $+20^{\circ}$ \\
\hline Antenna type & S-band, center-fed parabolic dish \\
\hline Circular reflector diameter & 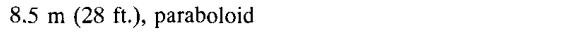 \\
\hline Beamwidth (one-way, $3 \mathrm{~dB}$ ) & $0.89^{\circ} @ 2.7 \mathrm{GHz}, 0.95^{\circ} @ 3.0 \mathrm{GHz}$ \\
\hline Gain & $45.5 \mathrm{~dB} @ 2.8 \mathrm{GHz}$ \\
\hline $\begin{array}{l}\text { Polarization } \\
\text { First sidelobe level }\end{array}$ & $\begin{array}{l}\text { Circular*: RH transmit LH receive } \\
-29 \mathrm{~dB}\end{array}$ \\
\hline Steerability & $360^{\circ}$ (Azimuth), -1 to $+45^{\circ}$ (Elevation) \\
\hline Rotation rate (max.) & $36^{\circ} \mathrm{s}^{-1}$ (Azimuth and Elevation) \\
\hline Angular acceleration & $15^{\circ} \mathrm{s}^{-2}$ (Azimuth and Elevation) \\
\hline Mechanical limits & -1 to $+60^{\circ}$ \\
\hline Pointing accuracy & $\pm 0.2^{\circ}$ \\
\hline Radome & Fiberglass skin foam sandwich \\
\hline Diameter & $12 \mathrm{~m}(39 \mathrm{ft})$ \\
\hline RF loss (2-way) & $0.3 \mathrm{~dB} @ 2.8 \mathrm{GHz}$ \\
\hline Transmitter frequency range & 2.7 to $3.0 \mathrm{GHz}$ \\
\hline Peak power output & $750 \mathrm{~kW}$ \\
\hline Pulse widths (nom.) & 1.57 and $4.5 \mu \mathrm{s}$ \\
\hline RF duty cycle (max.) & 0.0021 \\
\hline Pulse repetition frequency & Long : $318-452 \mathrm{~Hz} \quad$ Short: $318-1304 \mathrm{~Hz}$ \\
\hline Waveform types & Contiguous and batch \\
\hline Receiver tunability & 2.7 to $3.0 \mathrm{GHz}$ \\
\hline Bandwidth $(3 \mathrm{~dB})$ & $0.79 \mathrm{MHz}$ \\
\hline Phase control & Selectable \\
\hline Receiver channels & Linear output $\mathrm{I} / \mathrm{Q} \quad$ Log output $\mathrm{I} / \mathrm{Q}$ \\
\hline Dynamic range & $95 \mathrm{~dB}$ \\
\hline Noise temperature & $450^{\circ} \mathrm{K}$ \\
\hline Intermediate frequency & $57.6 \mathrm{MHz}$ \\
\hline Sample rate & $0.6 \mathrm{MHz}$ \\
\hline Signal processor & Hardwired/programmable \\
\hline Parameters & Reflectivity, mean radial velocity, Doppler spectral width \\
\hline Algorithm & Pulse-pair \\
\hline \multirow[t]{2}{*}{ Accuracy } & $1 \mathrm{~dB}$ (Reflectivity) \\
\hline & $1 \mathrm{~ms}^{-1}$ (Velocity and Spectrum width) \\
\hline \multirow[t]{2}{*}{ Number of pulses averaged } & 6 to 64 (Reflectivity) \\
\hline & 40 to 200 (Velocity and Spectrum width) \\
\hline \multirow[t]{2}{*}{ Range resolution } & 1 km (Reflectivity) \\
\hline & $0.25 \mathrm{~km}$ (Velocity and Spectrum width) \\
\hline Azimuth resolution & $1^{\circ}$ \\
\hline Clutter canceller & Digital, infinite impulse response \\
\hline Clutter suppression & 30 to $50 \mathrm{~dB}$ \\
\hline Filter notch half width & 0.5 to $4 \mathrm{~ms}^{-1}$ (Equiv. radial velocity) \\
\hline RPG processor & 32-bit general purpose digital computer \\
\hline Shared memory & $24 \mathrm{Mb}$ semiconductor memory Expandable to $128 \mathrm{Mb}$ \\
\hline Wideband communication & $1.544 \mathrm{Mb} / \mathrm{s}$ data base \\
\hline \multirow[t]{2}{*}{ Narrowband communication } & Up to $219600 / 4800$ bps 4-wire \\
\hline & Up to $269600 / 48002$-wire \\
\hline \multicolumn{2}{|l|}{ RPG Graphic display processor } \\
\hline \multirow[t]{3}{*}{ Communications } & Fixed point, 32 bit general purpose digital computer \\
\hline & Up to $59600 / 48002$-wire \\
\hline & Up to $39600 / 48004$-wire \\
\hline Video & Up to 4 auto call lines \\
\hline \multirow[t]{3}{*}{ Mass storage } & RS449/RS232 converters \\
\hline & Color, with split-screen and zoom functions \\
\hline & Up to two $140 \mathrm{Mb}$ disks \\
\hline
\end{tabular}

MAHAPATRA AND ZRNIĆ: SYSTEMS TO ENHANCE AVIATION SAFETY AGAINST WEATHER HAZARDS 


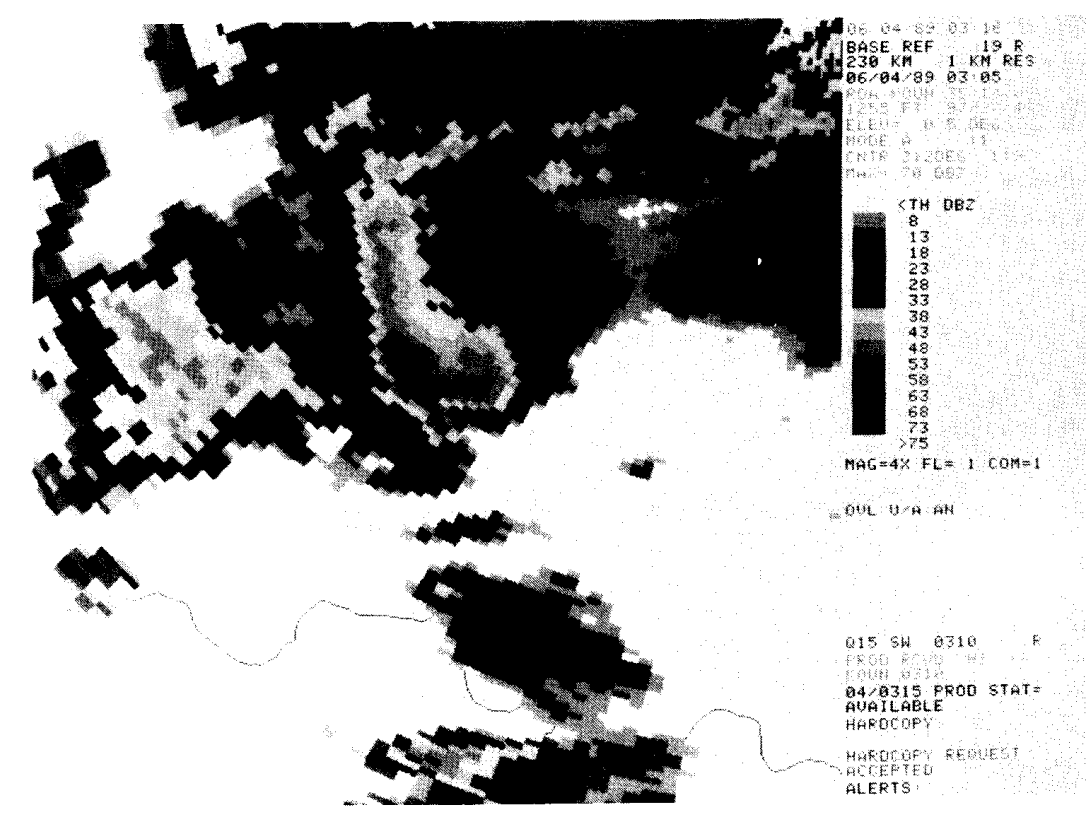

Fig. 12(a). Video display of the data products of a NEXRAD system. Reflectivity is shown as one of the moments displayed in the PPI format. The very dark patch just above the center is a precipitation core with reflectivity exceeding $68 \mathrm{dBZ}$. The actual display is in color.

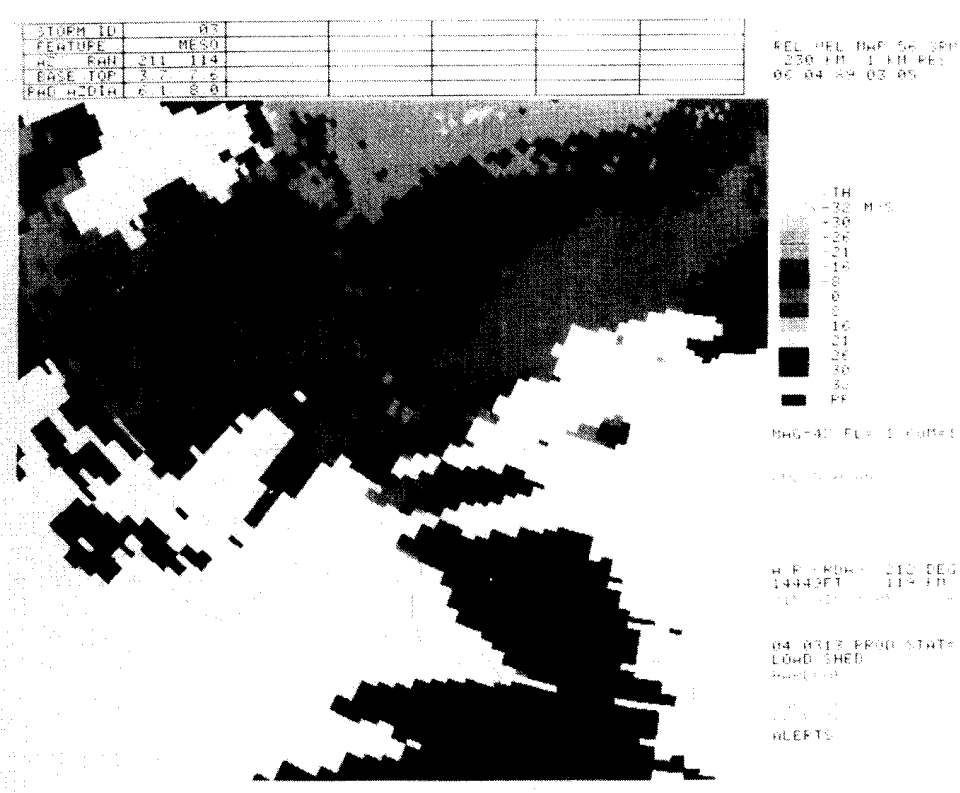

Fig. 12(b). Video display of the data products of a NEXRAD system. Mean radial velocity (of each resolution volume) is shown as one of the moments displayed in the PPI format. The circle at the center marks a mesocyclone that has been automatically detected. The actual display is color

lent precipitation [140]. However, it has the disadvantage of higher attenuation rates while propagating through heavy rain $\left(0.2 \mathrm{~dB} / \mathrm{km} @ 18^{\circ} \mathrm{C}\right.$ and $50 \mathrm{dBZ}$ reflectivity factor
[16]). The effect of such attenuation is to cause a significant underestimation of the reflectivity (and, therefore, precipitation intensity) at points which are screened from the radar

PROCEEDINGS OF THE IEEE, VOL. 79, NO. 9, SEPTEMBER 1991 


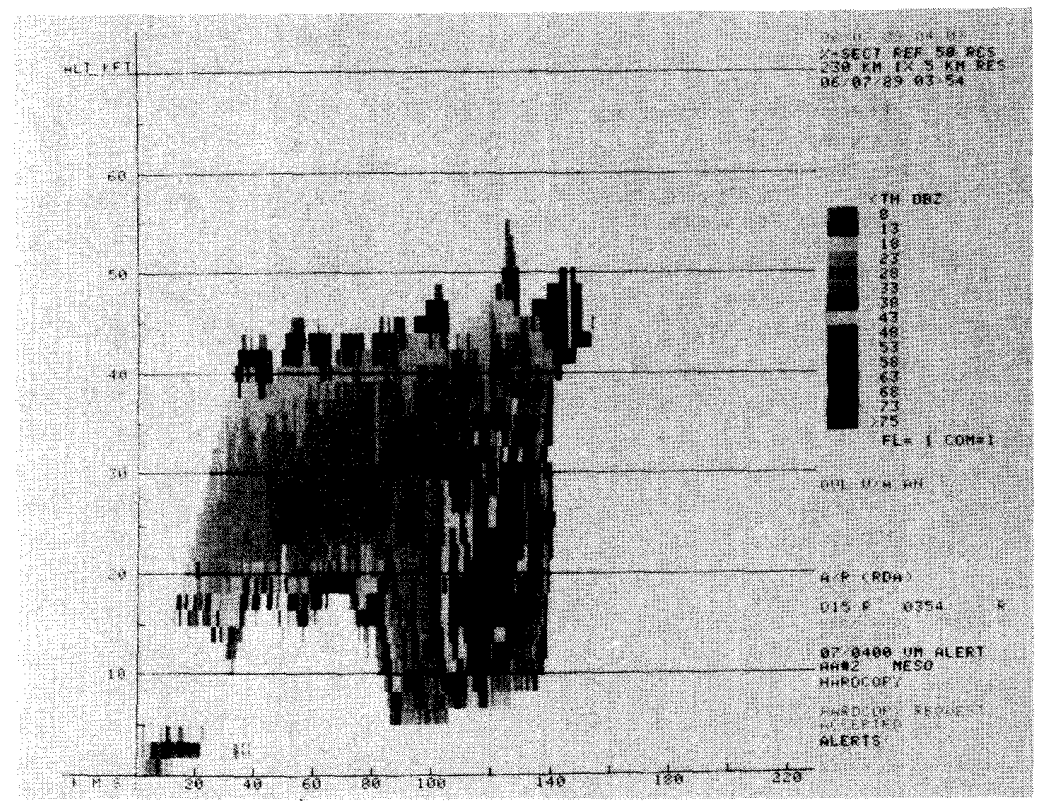

Fig. 12(c). Video display of the data product of a NEXRAD system. An RHI, obtained from scan data at different elevation angles, showing the vertical section through a thunderstorm. The actual display is in color.

by a thick layer of heavy precipitation [143]-[145]. Using the relationship between local reflectivity factor and the attenuation rate along the radar beam axis, it is possible to correct for the rain attenuation effects iteratively to a certain extent and up to some altitudes. However, to the extent that the reflectivity-attenuation relationship is uncertain, being dependent on temperature and hydrometeor size distribution, significant residual errors in reflectivity estimates may remain uncorrected [16]. The iterative correction procedures are known to be particularly sensitive to radar reflectivity calibration errors, even those as low as 1-2 $\mathrm{dBZ}$ [146], [147], which is the same order as stipulated for modern weather radars. This effect is pronounced at very high rainfall rates (corresponding to a reflectivity factor of the order of $60 \mathrm{dBZ}$ or more), which are precisely the rates most important for aviation. In fact, for such high rainfall rates, iterative correction schemes often become unusable, because of a tendency to diverge [146].

A $5-\mathrm{cm}$ wavelength also increases Doppler ambiguities. Attempts to solve this problem by increasing the pulse repetition frequency (PRF) results in a reduction of the unambiguous range of the radar. However, by a careful selection of the PRF, range obscuration from distant storms can be minimized over specified airport regions. Using data from a low PRF surveillance scan (in each cycle) having a $460-\mathrm{km}$ unambiguous range, it is possible to predict the obscuration as a function of PRF, and to automatically and adaptively select PRF's to best mitigate obscuration effects [140], [148].

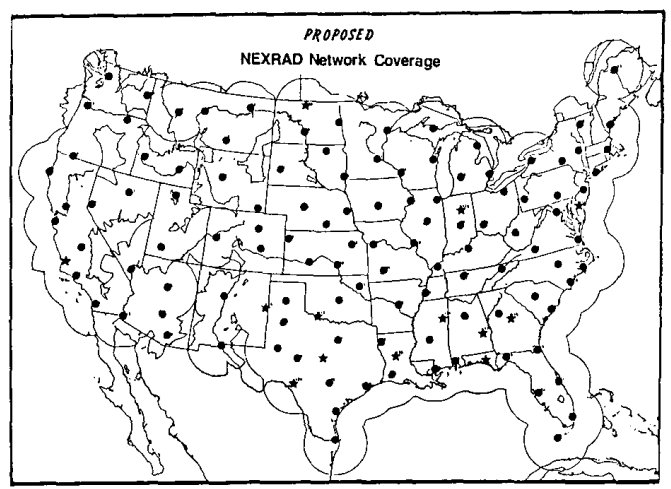

Fig. 13. Map of the continental U.S. depicting the proposal NEXRAD network coverage. Dots denote network sites and stars show the supplemental sites.

A major strength of the TDWR system is its design for automated operation with regard to the generation and dissemination of high-level weather products. This is possible with powerful software [149], to help the system detect and estimate the parameters of aviation-significant phenomena within its surveillance zone, and present the data, rapidly updated, to users in simple formats. The air traffic controllers will receive the data in an alphanumeric format, which is read to pilots. Data will be presented to supervisors in the control tower and the Terminal Radar Control (TRACON) in the form of a "geographic situation 
Table 3 TDWR Main ParametersM

\begin{tabular}{ll}
\hline \multicolumn{1}{c}{ Parameter } & \multicolumn{1}{c}{ Value } \\
\hline Frequency & $5.60-5.65 \mathrm{GHz}$ \\
$\begin{array}{l}\text { Range: Doppler } \\
\text { Reflectivity }\end{array}$ & $89 \mathrm{~km}\left( \pm 1 \mathrm{~m} \mathrm{~s}^{-1}\right.$ accuracy) \\
System Clutter Suppression & $560 \mathrm{~km}( \pm 1 \mathrm{~dB}$ accuracy) \\
Antenna Beamwidth & $55 \mathrm{~dB}$ \\
Gain & $<0.55^{\circ}$ (pencil beam) \\
Sidelobes Near In & $50 \mathrm{~dB}$ \\
Sidelobes Far Out & $-27 \mathrm{~dB}$ \\
Transmitter Power & $-40 \mathrm{~dB}$ \\
& $250 \mathrm{~kW}$ peak \\
Pulse width & $550 \mathrm{~W}$ average \\
PRF & $1.1 \mu \mathrm{s}(165 \mathrm{~m})$ \\
Receiver Linearity & $2000 \mathrm{~Hz}($ max.) \\
Noise Figure & $61 \mathrm{~dB}$ \\
Dynamic Range & $2.3 \mathrm{~dB}$ \\
STC & $129 \mathrm{~dB}$ \\
AGC & $26 \mathrm{~dB}$ \\
& $42 \mathrm{~dB}$ \\
\hline
\end{tabular}

display," in color, overlaying the location of microbursts and their wind speed differential, location and speed of gust fronts, and the location and intensity of precipitation on a plan of the runways and adjacent areas. Figure 14 shows an automatically detected gust front and Fig. 15 depicts a geographic situation display.

In addition to microburst detection, the monitoring of gustfronts and the resulting wind shifts in the airport area is an important functional requirement of the TDWR. The passage of gust fronts often results in sustained change in the prevailing winds, which has serious implications for airport operation, such as requiring changes in active runways, with consequent changes in the approach and departure corridors. To permit orderly change, ATC supervisors must be advised of the wind changes about $20 \mathrm{~min}$ before their actual occurrence [10]. The monitoring of wind shifts requires an estimation of the wind speed and direction behind the moving gust front, typically in low reflectivity regions [149]. The capability of the TDWR to observe over considerable distances outside the runway complex enables it to detect gust fronts before they move into the runway area, and provide the required warning time. As mentioned in the introduction, prior knowledge of wind shifts can result in great savings in fuel costs through proper flight management.

Much of the primary software for the TDWR has been subjected to extensive field testing at Denver's Stapleton International Airport and the Kansas City International

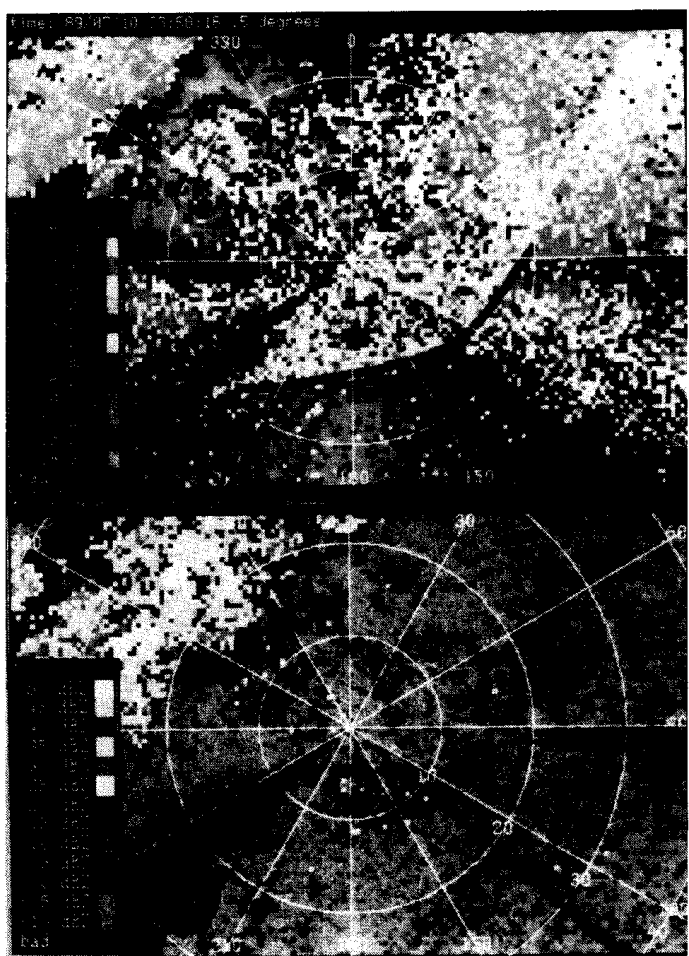

Fig. 14. A sample display of the radial velocity (top) and reflectivity (bottom) data from the TDWR system. The bold line on the velocity display denotes the gust front as recognized by an automatic gust front algorithm. Notice the extended region of sustained wind shift behind the gust front, and the weak reflectivity signature of the front. (Courtesy of Laurie G. Hermes.)

Airport. Extensive testing of detection algorithms using data from various sources has shown [138] that microbursts with differential velocities below $20 \mathrm{~ms}^{-1}$ are detected with about $90 \%$ probability, while the stronger ones with differential velocities exceeding $20 \mathrm{~ms}^{-1}$ are detected with over $98 \%$ probability. The false alarms were in the region of $4 \%-5 \%$. The detection of strong gust fronts (velocity differential $>15 \mathrm{~ms}^{-1}$ ) has a probability of $91 \%$, and the false alarm probability was as low as $2 \%$ for all gust fronts, based on data for Denver area. The FAA awarded a contract in 1988 for 47 TDWR's, with the option to procure 55 more systems later [99], [140]. Their installation is slated to begin at major U.S. airports prone to hazardous weather, in the early 1990's. The tentative locations of TDWR's in the continental U.S. are shown in Fig. 16.

A major advantage of radar weather surveillance over in-situ instruments is that radar observes the atmosphere at several elevation levels, making it possible to predict the occurrence of phenomena that have damaging effects at the ground level by observing precursors that may occur at higher levels. Indeed, precursor observation may be necessary to meet the official FAA requirement that a wind shear warning must be issued at least 1 min prior to the time that an airport will encounter "hazardous" 


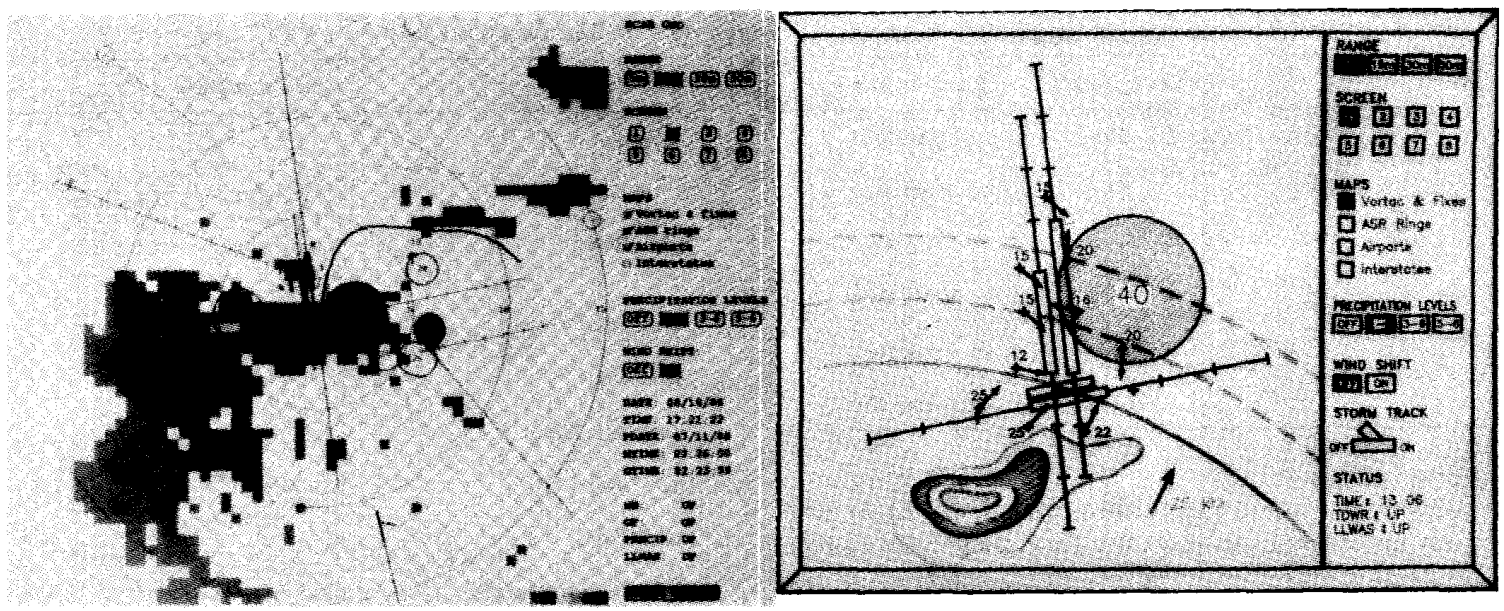

Fig. 15. (a) A sample Geographic Situation Display showing a composite map of the weather field and navigational features. The actual displays are in color. (b) Schematic of the details of the display in a zone around the runaway complex. (Courtesy of Laurie G. Hermes.)

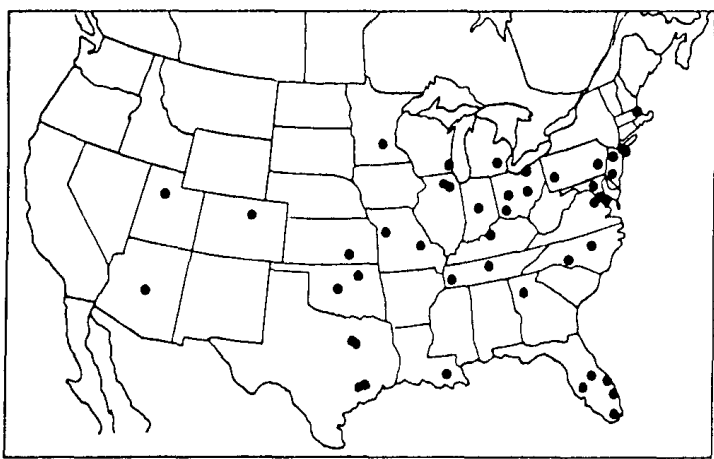

Fig. 16. Tentative placement of 47 TDWR's in the continental U.S. Site selection criteria include aviation activity levels and thunderstorm frequencies.

wind shear [10]. The possibility of microburst precursor observation has been practically verified in the case of the TDWR [150], [151]. In one particular trial, on the basis of the detection of a reflectivity core and rotation aloft, a microburst precursor signature was detected $9 \mathrm{~min}$ in advance of the surface outflow, and the microburst alarm itself was advanced in time by over one minute [149]. Even this order of improvement in the timeliness of hazard warning is considered significant in the highly dynamic environment of terminal area aviation operations.

3) The Airport Surveillance Radar with Dedicated Weather Channel: Weather radars dedicated to terminal area surveil- lance, such as the TDWR, should be located at or near airports for optimum performance. The airport surveillance radars (ASR's) required for the primary air traffic control (ATC) function, are also usually located close to the center of the runway complex. It is therefore logical to combine the functions of the two radars into one, which would minimize cost and complexity, and reduce demands on suitable sites, as well as frequency allocation. This is the basis of the evolution of the ASR-9 radar system with dedicated weather channel, under the sponsorship of the FAA. Also, for economic and climatological reasons, only a moderate number (47) of TDWR's will be installed in the U.S. in the near future. As ASR's are required at more airports, the inclusion of a weather channel in ASR-9 will provide radar surveillance of weather at a larger number of airports than will be equipped with TDWR.

Although a hybrid weather-ATC radar is functionally desirable, there are a number of major structural and operational differences between the optimal configurations of the weather radar and the ATC radar. The most important among them relates to the antenna patterns and scan cycles. The ATC radar typically has a fan beam scanning at a uniform elevation angle. In contrast, a typical Doppler weather radar has a narrow pencil beam, scanning at several levels. This difference has a strong bearing on vertical resolution, clutter rejection capability and signal processing. Further, whereas an ATC radar is usually near the center of the runway complex, the optimum site for an airport weather surveillance radar is about $10-12 \mathrm{~km}$ away from the complex [137]. A primary goal of the ASR-9 is to obtain an acceptable fusion of the weather and ATC functions in spite of such basic differences. 
Table 4 National Weather Service Standard Reflectivity Levels

\begin{tabular}{lcc}
\hline Level & Reflectivity (dBZ) & Rainfall Category \\
\hline 1 & $18-30$ & Light (Mist) \\
2 & $30-41$ & Moderate \\
3 & $41-46$ & Heavy \\
4 & $46-50$ & Very Heavy \\
5 & $50-57$ & Intense \\
6 & $57+$ & Extreme (Hail) \\
\hline
\end{tabular}

The current airport surveillance radars (ASR-8) do have a very limited weather capability. They can provide a single level outline of storms within their observation range, but the echoes are uncalibrated and nonquantized [152]; no detail or structure can be discerned within the displayed echo pattern. By contrast, the ASR-9 weather channel is designed to provide ATC personnel with accurate, quantized, clutter-free representation of the precipitation field. Six-level quantized reflectivity maps may be generated according to the National Weather Service (NWS) standards, shown in Table 4. The ATC personnel may select and display any two of the six levels.

A major improvement in the ASR-9 system configuration compared with previous and current ASR's is the use of separate receiver channels for weather reflectivity measurement and for aircraft detection [152]-[154]. Both linear and circular polarization are available on the ASR-9. The radar normally operates with linear (vertical) polarization in both transmission and reception. In this mode, the weather channel receives the same signal as the target channel. However, when weather reflectivity exceeding NWS level 3 (41 dBZ) is observed over large areas, the radar is switched over to the circular polarization mode to reduce interference due to rain echoes. In this mode, a very large portion of the weather echo has a polarization sense (i.e., left-hand circular or right-hand circular) that is opposite to the sense of the transmitted signal, whereas the target echo is divided almost evenly among both senses of polarization. The target channel receives circular polarization signal of the same sense as the transmitted signal, but the weather channel is connected to the orthogonal port of the polarizer to receive the oppositesense polarized signal. Such an arrangement reduces the polarization-induced loss of weather signal inherent in single-channel receivers optimized for aircraft detection (as in the current ASR's), and ensures near-optimal detection of both target and weather signals. A high degree of resistance to ground clutter interference is achieved by incorporating a clutter-map-controlled filter bank in the weather processor. Four filter choices are possible with different clutter-rejecting notches. These include a zerowidth notch (or "all-pass" filter) for areas without ground clutter. The key parameters of the ASR-9 system with regard to weather observation are shown in Table 5 [152]. A
Table 5 Operating Characteristics of ASR-9

\begin{tabular}{|c|c|}
\hline Parameter & Value/Description \\
\hline \multicolumn{2}{|l|}{ System: } \\
\hline Maximum Range & $110 \mathrm{~km}(60 \mathrm{nmi})$ \\
\hline Reflectivity & $\begin{array}{l}\text { Six-level, two selectable for } \\
\text { display }\end{array}$ \\
\hline \multicolumn{2}{|l|}{ Transmitter: } \\
\hline Frequency & $2.7-2.9 \mathrm{GHz}$ \\
\hline Transmitter Type & Klystron \\
\hline Peak Power & $1.10 \mathrm{MW}$ \\
\hline Pulse Width & $1.0 \mu \mathrm{s}$ \\
\hline \multirow[t]{3}{*}{ Signal Format (typical) } & Block Stagger Mode \\
\hline & 8 pulses@940 Hz \\
\hline & 10 pulses@1200 Hz \\
\hline \multicolumn{2}{|l|}{ Receiver: } \\
\hline Noise Figure & $4.1 \mathrm{~dB}(\max )$ \\
\hline Sensitivity & $-108 \mathrm{dBm}$ \\
\hline A/D Word Size & 12 bits \\
\hline Range sampling & $115.8 \mathrm{~m}$ \\
\hline Clutter Rejection & $45 \mathrm{~dB}$ \\
\hline No. of clutter filters & $\begin{array}{l}\text { 4, Variable-notch-width } \\
\text { (clutter-map controlled) }\end{array}$ \\
\hline \multicolumn{2}{|l|}{ Antenna: } \\
\hline No. of fan beams & 2 , vertically stacked \\
\hline \multirow[t]{2}{*}{ Beam Width $(-3 \mathrm{~dB})$} & Elevation: $6^{\circ}\left(\min .4 .8^{\circ}\right)$ \\
\hline & Azimuth: $1.4^{\circ}$ \\
\hline Beam separation & $3.5^{\circ}$ in vertical plane \\
\hline Polarization & Vertical/Circular \\
\hline Antenna Gain & $34 \mathrm{~dB}$ \\
\hline Scan Rate & $12.5 \mathrm{rpm}$ \\
\hline
\end{tabular}

very advantageous feature of the ASR-9 system design is its capability of unattended operation, including facilities for remote performance monitoring, fault isolation, and control. Over a hundred ASR-9 radars, of which the first was commissioned in May 1989 are to be installed in the U.S.

The ASR-9 has a dual beam antenna (with two fan shaped beams separated in elevation), scanning in azimuth only. It has a very rapid scan rate $(12.5 \mathrm{rpm})$, and hence the raw weather data can be updated nearly every five seconds. However, data smoothing to reduce statistical fluctuations results in an operational update rate of the order of half a minute. Fast data update is a very strong point of the 
ASR-9, which makes it unique among the three weather radars important in the aviation context. With such current data, and a six-level reflectivity map over a radius of 11 $\mathrm{km}$, the ASR-9 can provide very useful weather data inputs for flight management over the most critical part of the terminal areas. The weather picture over and around the runway complex can potentially be made more complete by combining the ASR-9 data with those from the TDWR and any suitably located WSR-88D(s).

An optional processing channel has also been developed for the ASR-9 to automatically detect regions of lowaltitude wind shear. The augmented ASR-9 has been shown to be able to perform adequate clutter suppression, estimation of near-surface radial wind velocity, and automatic wind shear hazard detection in the case of wet microbursts. Using a spectral differencing scheme between a low and a high beam in the vertical plane, detection probabilities higher than $90 \%$ and false alarm probabilities less than $4 \%$ have been achieved for microbursts occurring within a range of $12 \mathrm{~km}$ and having a velocity differential over $10 \mathrm{~ms}^{-1}$ in their divergent outflows. The performance is significantly better for more intense microbursts [155]. The addition of this processor would potentially upgrade the ASR-9 to a level that it can be used in a stand-alone mode for wind shear warnings at airports where a dedicated TDWR is not justified, based on traffic density and/or microburst frequency. Although the wind shear detection capability is optional in the case of ASR-9, it will, in all probability, be a built-in function in future airport radars.

\section{Other Sensors of AtMospheric Parameters}

Doppler weather radars are elaborate and expensive equipment which cannot be installed everywhere, and there will always be a considerable amount of aviation activity that will not have the benefit of these systems. Areawise, WSR-88D coverage will, of course, be available over nearly all of the continental U.S., but low altitude coverage (because of radar horizon limitations) and resolution of these radars will be inadequate for terminal area aviation support, except in small zones around each radar. There is thus need for additional instrumentation that can be more widely distributed. These can supplement Doppler radar data where their effective areas overlap, and can form the chief source of information about wind shear and shifts where Doppler radar support is not available.

\section{A. Wind Profilers}

A very significant form of atmospheric wind shear from the point of view of aviation safety is the vertical wind shear, i.e., the vertical variation of horizontal wind speed and direction. A schematic of this form of wind shear and its effect on aircraft has been shown in Fig. 1. An instrument that can measure such wind variations is called a wind profiler.

A conventional method of wind profiling in the lowest few hundred feet of the atmosphere is by anemometers mounted on tall instrumented towers [156]. Profiling up to higher levels is done by releasing a balloon and tracking its movement with a precision radar. The balloon method has been used by, for example, NASA in support of its launch operations at the Kennedy Space Center, where it is possible to obtain wind profiles up to $18 \mathrm{~km}$ altitude with $50 \mathrm{~m}$ resolution and $1 \mathrm{~ms}^{-1}$ accuracy [157]. However, the balloon method of profiling is very slow, taking 1-2 h per operation, and the wind profiles are obtained only along the balloon's flight path which cannot be controlled. A more modern approach, providing measurements of wind with much higher spatial and temporal resolution, is to use electromagnetic profilers which remotely sense the wind speed variations with height.

Electromagnetic profiler development started seriously only about a decade ago, but has attained a very high degree of maturity within the short period. These are essentially atmospheric Doppler radars, but are far less versatile-and consequently simpler and less costly - than the radars described in the previous section. They usually do not have steerable antennas, but have a few fixed beam positions close to the vertical direction, e.g., as in Fig. 17. It is common to have one vertical beam position, accompanied by a few (2-4) oblique beam positions at about $75^{\circ}$ elevation relative to the horizontal. The vertically pointing beam would sense only the vertical component of the wind at all levels within its altitude coverage range. The oblique beams would be sensitive to their along-axis components of the vertical as well as the two horizontal velocity components. Assuming the wind field in each layer to be uniform, the orthogonal wind components can be estimated by processing signals from three nonplanar beam positions (usually one vertical and two oblique beams). As the different beam positions record wind components at physically separated points (the separation may be as much as a few kilimeters at higher altitudes), nonuniformities in wind fields can cause significant errors in the estimation of wind velocity components. Some of the errors can be compensated by using more beam positions than the minimum of three positions that are necessary to estimate the wind components under ideal conditions. Proper signal processing and data averaging schemes [158] can minimize the effects of noise and random wind fluctuations, as well as wind nonuniformities, on profiling accuracy.

Electromagnetic profilers are designed to receive echoes primarily from the refractive index fluctuations in the atmosphere, caused by inhomogeneities in temperature and water vapor. In particular, most echo power is returned by the component of the fluctuations in the neighborhood of a half of the spatial wavelength of the profiler, along the radial direction. Profilers typically utilize frequencies in the VHF/UHF bands, rather than microwave frequencies, because the longer wavelengths provide higher echo returns from the refractive index fluctuations associated with relatively large eddies that are in the inertial subrange, and do not dissipate rapidly. Centimeter-scale eddies, which are efficient scatterers at microwave frequencies, dissipate rapidly after their creation, due to viscosity effects. Hydrometeors, such as rain, are not considered to be good 

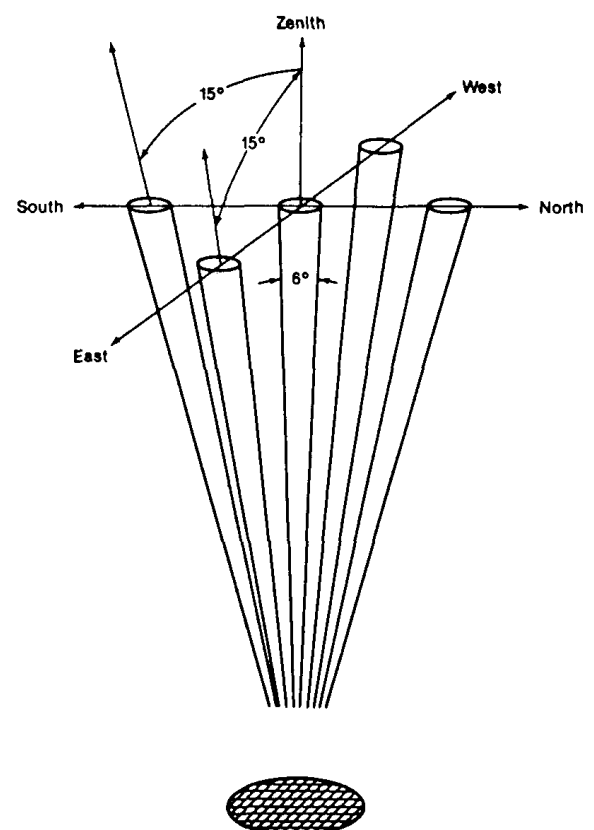

405 MHz PHASED ARRAY

Fig. 17. Example of multiple discrete positions of a profiler beam. The center beam position points vertically upward. The diagram corresponds to the Platteville $405 \mathrm{MHz}$ profiler operated by NOAA's Wave Propagation Laboratory.

tracers for profiling because they are not present at all altitudes at all times, and because their considerable fall velocity introduces additional Doppler shift, affecting the accuracy of wind estimates [159]. The use of the longer wavelengths in the VHF/UHF bands significantly reduces echoes from hydrometeors. However, the estimates may still be perceptibly affected by strong precipitation.

The conflicting requirements of electromagnetic profilers in terms of operating frequency, antenna size, altitude coverage, etc. have led to the development of different types of profilers in the U.S. [160], [161]. The most familiar type is the Tropospheric Wind Profiler, which is a clear-air radar operating at $404.37 \mathrm{MHz}$ (roughly stated as $405 \mathrm{MHz}$ ) that can measure wind profiles from near the surface to a height of about $17 \mathrm{~km}$, covering the entire troposphere and the lower stratosphere. A prototype profiler of this type has been operating at Platteville, CO, since September 1988, and this type of profiler is produced commercially. The instrument can operate automatically and continuously, and produces profiles every hour with a height resolution of about $1500 \mathrm{ft}(500 \mathrm{~m})$, and a $1 \mathrm{~ms}^{-1}$ accuracy for horizontal wind components. A network of 30 such profilers is about to be installed in the central U.S. (Fig. 18), which will help determine their usefulness in improving weather prediction, and the desirability of a national network of profilers. Based on the results of a 5-profiler network [162], it is expected that wind data from a larger network will find wide use

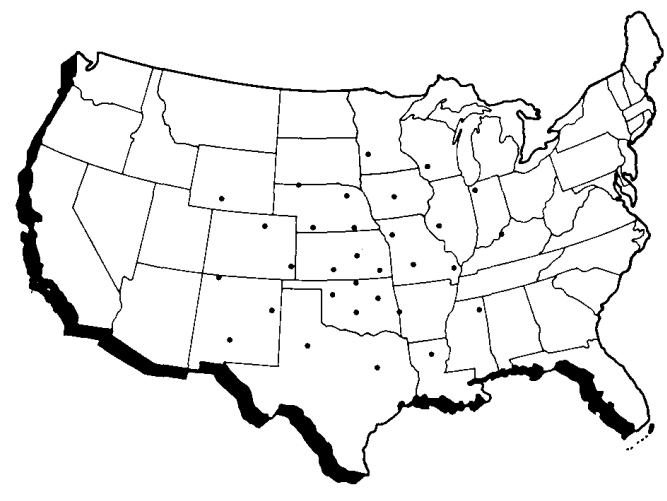

Fig. 18. Locations of $405 \mathrm{MHz}$ tropospheric wind profilers in a network to be deployed in the central U.S

in air traffic routing, especially of commercial airliners, to avoid or take advantage of jet streams (depending on the jet stream direction relative to flight heading), in addition to general weather forecasting.

Very useful information about vertical wind shear and windshifts in support of aircraft approach, landing, and takeoff operations in terminal areas may be obtained by suitably locating a wind profiler within the airport area. Such profilers, unlike the tropospheric profilers, need a height coverage only up to a maximum of 4-6 km, within which all terminal area operations are conducted. As clearair reflectivity (i.e., echoes due to refractive index fluctuations) is generally much higher in the lower troposphere, the Lower Tropospheric Wind Profilers (as these loweraltitude profilers are called) can have a lower sensitivity and a higher frequency than the tropospheric profiler, and also have finer height and time resolution for their data, of the order of $450 \mathrm{ft}(150 \mathrm{~m})$ and $10 \mathrm{~min}$, respectively. Research profilers of this type have been built at 405 and $915 \mathrm{MHz}$; one of the latter type has been operating at Denver's Stapleton airport since 1983 [161]. The relatively high operating frequency and low sensitivity of lower tropospheric wind profilers make them more affordable and transportable [163].

It is possible to achieve further simplicity and compactness of equipment by confining attention to an even lower layer of the atmosphere than the lower tropospheric profiler. Profilers ${ }^{*}$ which provide wind data up to about 2 or $3 \mathrm{~km}$ of altitude are called Boundary Layer Profilers. Even such a height coverage will be quite adequate for a large part of terminal area aviation operations. Ecklund et al. [164] describe a boundary layer profiler operating at $915 \mathrm{MHz}$ which has an antenna small enough to be mechanically steered, providing a much greater degree of flexibility in profiling than fixed-beam profilers. In addition to good height and time resolution $(300 \mathrm{ft}$ or $100 \mathrm{~m}$, and $10 \mathrm{~min}$, respectively), a major advantage of this profiler is that its higher frequency and bandwidth permit the measurement of winds much closer to the surface (down 
to about $300 \mathrm{ft}$ or $100 \mathrm{~m}$ ) than is possible with other profilers. The advantage of profiling down to such low levels is particularly important in the context of terminal area aviation, because it is wind shear at such low levels that poses the most hazard to aircraft during landing and takeoff. The biggest advantage of the boundary layer profiler over other types, however, is its much lower cost, resulting from its simplicity and compactness. An estimate of the cost of boundary layer profilers puts it in the range of $\$ 40000-60$ 000 (1987 dollars) as compared with $\$ 120000-150000$ for a lower tropospheric wind profiler and $\$ 350000-450$ 000 for a tropospheric profiler [161]. Such a low cost makes the boundary layer profiler an attractive proposition for being included in automated weather stations even for small airports which may primarily support general aviation.

For the sake of completeness, mention may be made of a much larger type of profilers called the StratosphericTropospheric profilers with height coverage up to about 20 $\mathrm{km}$ and a high degree of resolution in height (450 ft or 150 $\mathrm{m})$ and time $(10 \mathrm{~min})$. These profilers necessarily operate at a lower frequency, of the order of $50 \mathrm{MHz}$, are expensive (cost \$3-5 million), but have been justified in the context of supporting space vehicle launch operations [161], [165], in addition to scientific research.

Wind profilers do have certain important limitations which arise from the spatial separation of their beam positions, the assumptions made regarding the uniformity of wind fields, the existence of upper and (more importantly) lower bounds to altitude coverage, and susceptibility to errors due to precipitation. In particular, profilers perform relatively poorly in stormy conditions which usually involve both precipitation and turbulent wind fields. Microwave Doppler radars using centimeter wavelengths appear to be able to perform profiling under such conditions [166].

In spite of their current limitations, profilers can be very effective in providing wind shear and wind shift information of direct significance to aviation. Figure 19 [161] shows the time-height plot of two wind fields as seen by radar profilers. It is easy to see that such a detailed picture of the vertical structure of the atmosphere even in the absence of precipitation will be very beneficial in flight management for safety and economy, especially in the terminal areas. The utility of profilers is particularly high in situations where radar coverage of adequate quality is not available, but they can very usefully supplement radar data even where such coverage is available. Besides being optimized for clear-air observation, profilers provide wind information in a vertical direction, which is within the "blind zone" (the conical space above a radar that is not scanned) of the Doppler weather radars in their normal operating modes. The promise held by the profiler has prompted many nations around the world to seriously consider its usage in support of their aviation systems [167].

\section{B. Radio Acoustic Sounding and Sensing of} Aircraft Icing Conditions

A useful augmentation of the profiler radars is the Radio Acoustic Sounding System (RASS) which can measure

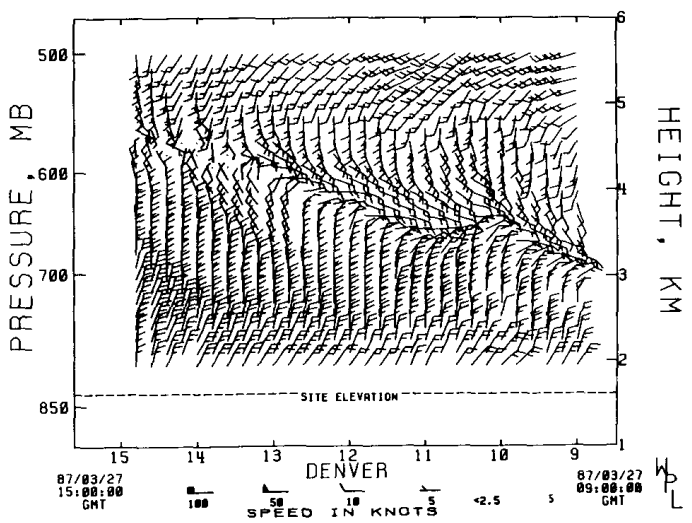

(a)

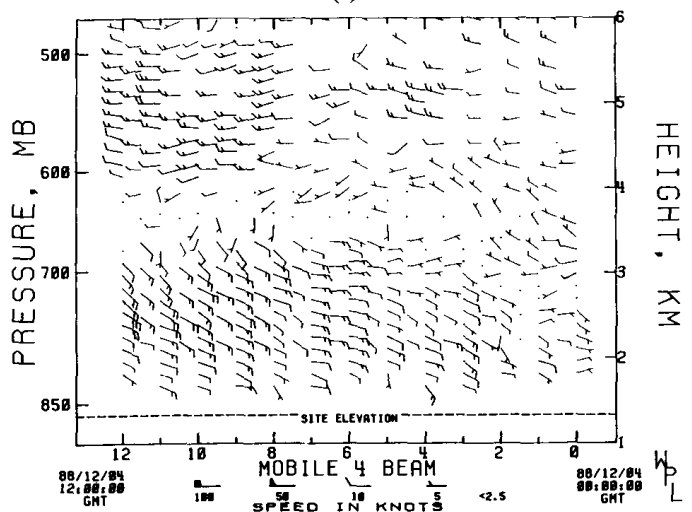

(b)

Fig. 19. Examples of wind profiles (versus time) obtained by radar profilers: (a) data from a $915-\mathrm{MHz}$ profiler at Denver's Stapleton International Airport showing a frontal passage, (b) data from a $405-\mathrm{MHz}$ profiler at Fort Huachua, Arizona, showing a wind reversal with altitude, with a shear zone at about $4-\mathrm{km}$ altitude. (Courtesy of Dr. Richard G. Strauch.)

temperature profiles in the lower troposphere [168], [169] by measuring the propagation speed of an acoustic grating (wave train) that scatters electromagnetic waves via the Bragg effect. Atmospheric temperature profiles are very useful in the context of aircraft icing. It is known that hazardous conditions from the point of view of ice formation on aircraft are most often found at temperatures between -10 and $0^{\circ} \mathrm{C}$, and current RASS, with temperature profiling accuracies better than $0.7^{\circ} \mathrm{C}$, can help delineate such zones [170]. Profiling radars operating at 50,405, and $915 \mathrm{MHz}$ have been used in RASS's. The altitude ceiling of temperature profiling is about $10 \mathrm{~km}$ for the lowest frequency. It is lower for the higher frequencies, because of stronger attenuation of higher frequency sound waves (higher radio frequencies require higher audio frequencies for sounding).

Accurate prediction of aircraft icing conditions requires knowledge of the distribution of supercooled liquid water in the atmosphere, which can be derived from the vertical profiles of temperature and liquid water concentration. The latter, as well as the water vapor content, can be obtained 
by dual-wavelength microwave radiometers operating at 21 and $32 \mathrm{GHz}$ [171], [172]. A combination of RASS and dual-channel microwave radiometer is thus a potent method of monitoring aircraft icing conditions, but may be further augmented by any or all of the following for more detailed and accurate nowcasting: 1) airborne radiometer (for horizontal distribution of supercooled liquid water), 2) Doppler radars (for mapping supercooled liquid water distribution and water vapor flux), 3) lidar (a radarlike instrument utilizing laser radiation, useful for remote sensing of winds, temperature, water vapor concentration, and cloud-base height), and 4) GOES satellite data (for cloud top temperature, see a later section in this paper) [170], [173]. FAA's Icing Research Program aims to utilize ground-based as well as airborne instrumentation to detect icing conditions and attempt to forecast icing, initially up to $4 \mathrm{~h}$ and later up to $12 \mathrm{~h}$ [99].

\section{The Low Level Wind Shear Alert System}

One of the earliest instruments used for the in situ measurement of wind is the anemometer. In its most common form, it consists of a few (typically three) cups or vanes mounted on a smoothly rotating shaft. The rotational speed of the anemometer is a monotonic function of the local wind speed, and therefore serves as a measure of the wind speed. The wind direction can be sensed by a device similar to a weathercock. Modern anemometers have electrical transducers which help remotely monitor their readings. Because of its ability to provide vector winds, the anemometer-weathercock combination is a very useful instrument, but its chief limitation is that it can sense winds at only one point. This drawback can be overcome, and a more complete picture of the wind field generated, using an array of anemometers. The Low Level Wind Shear Alert System (LLWAS), which has been in routine operation at airports in the U.S. over the past decade, is a system based on an anemometer array that is specifically designed and operated for aviation support.

The LLWAS was conceived as a response to the weatherinduced air disasters of the 1970's such as the Eastern Airlines accident [63] at JFK in 1975, many of which were attributed to low-altitude wind shear. Phenomena that generate wind shear at very low altitudes (in the lowest few hundred meters) generally produce a ground-level signature which should serve as a warning for the existence of the shear. The LLWAS is designed to detect these signatures.

The original version of LLWAS [174] is an anemometer array consisting of one anemometer located close to the center of the airport's runway complex and five more anemometers at outlying spots located, where possible, close to the approach paths of individual runways. Each anemometer is placed on a mast at a height of 4-20 m above the ground depending on the local air flow quaity (velocity perturbations, turbulence, etc.) and obstruction considerations. A central processor monitors the individual anemometer readings through a radio link at $10-$ s intervals. A wind shear advisory is issued if any of the outlying anemometers shows a wind speed difference of more than
$15 \mathrm{kt}$ with respect to the two-minute averaged reading of the centerfield anemometer.

The LLWAS was originally slated to be an interim solution for wind shear warning, to be eventually replaced by essentially Doppler radar based systems. Specifically, the initial design of LLWAS was to satisfy the requirement of detecting wind shear associated with gust fronts and other nonthunderstorm frontal phenomena [175]. The LLWAS was first installed in 1977-1978, and as many as 103 airports have been equipped with the system. There are plans to take that number to 110 . The LLWAS is no more regarded as an interim solution for wind shear detection, but has been incorporated as an element of the FAA's Integrated Windshear Program Plan of 1987 [176]. Certain deficiencies of the original (or "basic") form of LLWAS have been known [16], [38]. The system is being improved to overcome these limitations, and to enhance its role in wind shear detection. The deficiencies essentially result from the small number of sensors in the basic system as well as their location. The enhancement of the LLWAS' role includes the detection of microbursts. Improvements to the LLWAS are being made in many respects. These include [175], [177] network expansion (i.e., adding more sensors to the original six), network and software design enhancements to identify microbursts and gust fronts, and provide runway-oriented wind shear information, and the elimination of site effects on wind sensors [178]. Two enhanced "test bed" systems have been operating at New Orleans and Denver airports since 1984 and 1985, respectively. An enhanced array of 12 sensors tested at Denver, along with a wind shear and microburst detection algorithm, has been found to perform better than the conventional method of merely comparing the outer sensor readings with the averaged centerfield sensor reading [179].

The LLWAS, irrespective of its configuration, will have certain drawbacks inherent to ground-based in situ sensors. An important limitation is that surface winds detected by the LLWAS sensors may be significantly different from those at the heights at which aircraft may encounter wind shear during terminal area operations. In a recent study [180] it has been found that winds at a few hundred feet (even as low as about a hundred feet or $30 \mathrm{~m}$ ) above ground are on an average about $60 \%$ higher than those at heights corresponding to the location of the LLWAS sensors. As wind effects on aircraft vary as the square of wind speeds, this difference between the true and the surface-sensed winds could be highly significant. Thus whereas LLWAS warnings will be useful at airports without Doppler radars, the most efficient use of LLWAS data may be in conjunction with those from Doppler radars wherever joint coverage is available, because the LLWAS can provide wind data at the lowest levels, at which radar data are often unreliable due to ground clutter contamination and radar horizon limitations.

\section{Airborne Wind Shear Detection}

The systems for wind shear detection discussed up to this point are ground-based, requiring information to be transmitted to the aircraft. Sensing the shear in the aircraft 
itself makes it autonomous, cutting down the need for extensive ground-based support facilities, communication, and attendant delays. Wind shear may be detected by aircraft either in situ or via remote sensing. In the former, air motion is sensed by measuring its effect on the aircraft motion parameters and dynamics [181]. Perturbations in aircraft motion and attitudes are readily detected by inertial sensors which are now used in all but the simplest general aviation aircraft. Using these sensed data and the dynamical equations of aircraft motion, the inputs due to wind changes may be estimated.

Although the in situ detection of wind shear by aircraft is quite straightforward, it has the drawback that the aircraft would notice the shear only when it actually begins to enter the shear field. Airborne shear detection does provide useful warning time to the pilot before maximum levels of shear are encountered, and also facilitates the incorporation of automatic compensation mechanisms to mitigate the effects of shear. However, it is desirable to sense wind disturbance along the flight path remotely from the aircraft, which would provide a longer warning time to the pilot to take remedial measures. This is currently an active area of research and development. The FAA, in conjunction with NASA, has a program on airborne wind shear detection and avoidance, covering all its aspects: hazard definition, sensor assessment, and flight management and integration [99]. Among the airborne instruments to be studied are lidar, radar and infrared sensors, attention devoted to aircraft simulation, mesoscale modeling and analysis, and instrumented flight tests.

\section{E. Automated Weather Observing System}

Meteorological operations have traditionally depended on in situ observations, i.e., the use of instruments that sense atmospheric parameters in their immediate vicinity. The parameters usually include such fundamental quantities as temperature, dew point, pressure, humidity, wind speed and direction, rainfall rate and accumulation, etc. In the specific context of aviation, certain other parameters such as airport local visibility, visibility ceiling, sky condition, runway wetness or ice covering, etc. are also observed and recorded. However, such observation has hitherto been human-centered, i.e., although the quantities are sensed using physical instruments, all subsequent steps in the data chain, such as recording, interpretation and dissemination, require direct and routine human intervention. This necessity makes the weather observation system expensive, and, in the aviation context, slow.

To improve the accuracy and currency of weather data and reduce operational costs, the Automated Weather $\mathrm{Ob}$ serving System (AWOS) concept is being introduced into the aviation system, and incorporated into the Federal Aviation Regulation (FAR), to perform measurement, processing and direct dissemination of weather observations to pilots without any routine human involvement [182].

The AWOS is designed primarily to provide accurate, real time weather information to pilots in support of landing and takeoff operations. To this end, the AWOS sensors will be located in the touchdown area of the runway to accurately represent conditions to be encountered by aircraft. The system processor updates the data continuously, providing highly current data to pilots directly through computergenerated voice. This would eliminate the need for interactive or query-response mode of information dissemination, reducing time delays and pilot work load during the critical phases of takeoff and landing operations. Under the FAR, the FAA has established a policy that stipulates three levels of AWOS implementation [182]. The AWOS-1 reports altimeter setting, wind, temperature, dew point, and density altitude. The AWOS- 2 provides visibility data in addition to AWOS-1 observations. Further addition of ceiling/cloud height data comprises the capability of AWOS-3. Definite rules have been stipulated regarding the approval of these systems for usage at different classes of airports. The systems are designed on a modular basis, such that additional sensors can be integrated readily.

AWOS's may be procured and operated by the Federal government or other agencies, but all procurement must be from FAA-certified sources. The spread of AWOS's may be gauged from the fact that Federal AWOS's are being procured off-the-shelf for 160 airports, and that there are over 70 airports that already have or are in the process of obtaining non-Federal AWOS's, mostly supported through the FAA's Airport Improvement Program grants to states and local airports [182]. The Automated Surface Observing System (ASOS) is an interagency program between the NWS, FAA, and DoD that is functionally quite similar to the AWOS, but may use somewhat different hardware. The deployment of ASOS's is slated to start by mid 1990, and over the next five years over 600 airports are expected to be supported by the Federal ASOS program. Many nations other than the U.S. (e.g., [183]) are also building up networks of automatic weather stations in support of their aviation programs.

These automated systems will potentially offer a simple and cost effective method of providing accurate and current data regarding airport weather to aircraft, and therefore will be available at many more airports across the nation than the more expensive monitoring devices. However, certain limitations of these systems are already apparent. These arise essentially from the nonuse of human perception, intelligence, and subjective judgement in the automated system. Thus at least in the near future, reportings from unmanned locations will not contain remarks about the prevailing visibility (e.g. quadrant-wise visibility differences), present weather type and sky condition, cloud types, etc. However, further developments in sensors and artificial intelligence methods, and the modular architecture of the automated systems, should eliminate some of these drawbacks in course of time.

\section{F. Satellite Observations}

Satellite observation of weather patterns, both as multispectral (visible and infrared) imagery and sounding data, has provided very valuable inputs to weather monitoring, modeling and forecasting on global as well as regional basis 
over the last three decades. The large coverage of the fields of view of satellites enables them to track the evolution of large scale features such as tropical cyclones, movement of weather systems, cold/warm fronts, etc. However, in the context of weather nowcasting for aviation support, satellite observations have lacked both spatial and temporal resolution. For example, the currently operational Geostationary Operational Environmental Satellites (GOES) of the National Oceanic and Atmospheric Administration (NOAA) have spatial resolutions of $1 \mathrm{~km}$ in visible band imaging, $8 \mathrm{~km}$ in infrared imaging and $14 \mathrm{~km}$ in sounding. The last two are inadequate for the detection of smallscale phenomena such as microburst-producing cells, which are of importance to aviation, though they are very useful for observing mesoscale convective complexes, which are responsible for much of the weather activity over large parts of the U.S. [184,185]. The visible band does often show gust fronts or thunderstorm outflow boundaries in the form of arc clouds [186] and buoyancy ("gravity") waves generated by these outflows [187]. It also shows the parent storms or storm systems that create strong wind shear or turbulence, e.g., in the case of the 1985 Dallas-Fort Worth accident [74], but the details are usually not sufficient to be used by themselves for specific and localized aviation hazard warning. Satellite reports, which are usually updated at intervals of $30 \mathrm{~min}$ or $1 \mathrm{~h}$, are too slow for the dynamic environment of aviation. Satellite data, including soundings, have, however, been used to determine the environmental conditions of storms [188]. The use of satellite data for local forecasting [189] can help increase the efficacy of dedicated aviation weather instrumentation by increasing their level of alertness and adjusting their operational parameters during times of anticipated weather activity.

Many of the resolution-related parameters of satellite observation will improve with the scheduled improvement of the satellite systems. The GOES I-M series of 5 satellites, which will be improved versions of the current GOES satellites, are slated for launch between 1990 and 1997. These will be 3-axis stabilized satellites with much higher weight ( 3 times) and electrical power output (30 times) than current satellites. They will have significantly higher number of imager and sounder channels, better resolution in infrared imaging (4 km versus the current $8 \mathrm{~km})$, sounding $(8 \mathrm{~km}$ versus $16 \mathrm{~km}$ ) and gray scale (1024 versus 64 shades) [190]. Most importantly, the new satellites will have a flexible scanning scheme which will greatly improve the data update rate in times of necessity. Thus the GOES I-M will normally take images every $30 \mathrm{~min}$, but the interval will be reduced to $15 \mathrm{~min}$ a few hours before the occurrence of severe weather, and to a rapid scan rate of once every $5 \mathrm{~min}$ just before and during the occurrence of severe weather. For the imager, it is even possible to perform a super-rapid scan of statesized areas at about 30-s intervals [186], [191]. Thus the spatial and temporal resolution scales of satellite weather observation are gradually being refined to cover scales of phenomena that are significant for aviation. With these improvements, the utility of satellite data in local severe weather nowcasting should be significantly enhanced [190].
VI. CONSIDERATIONS For MUlTISENSOR OBSERVATION OF AVIATION WEATHER

The foregoing sections provide an indication of the high level of activity being carried out in developing advanced electronic sensors and systems for improvement of aviation safety and efficiency. These sensors will provide vast amounts of weather data, much of it in real time. During the 1990 's, when all the systems currently under development are put into operation, data for specific use in connection with aviation safety, economy, and efficiency will come from the following sources: 1) AWOS and ASOS, 2) LLWAS, 3) vertical wind profilers, 4) TDWR, 5) ASR9 weather channel, 6) WSR-88D, 7) satellite imaging and sounding, and 8) formal pilot reports (PIREPS) from all aircraft using a particular runway/airport/route. These data will be in addition to those from traditional sources such as the networks operated by NWS and DoD, and the temperature, pressure, and wind readings from airborne automatic reporting units being installed on an increasing number of commercial aircraft. Most major airports of the U.S., and a major fraction of its geographical area, will be covered simultaneously by a multiplicity of instruments with considerable overlap in their measurement functions. In a certain sense, at the end of the current expansion phase, aviation weather surveillance has the prospect of being an over-instrumented rather than an under-instrumented field!

In the evolving aviation weather scenario, diverse highly processed (e.g., from TDWR), semiprocessed (e.g., WSR88D, LLWAS), direct (AWOS/ASOS, airborne automatic reporting systems), and qualitative (PIREPS) information would be reaching pilots/controllers in environments that are even otherwise quite demanding. There is, thus, need to establish proper rules of information flow in terms of hierarchies, priorities and protocols so that the redundant data set is optimally utilized in enhancing the quality of aviation.

Mechanisms to streamline the aviation data flow are incorporated into the National Airspace Systems Plan, which will make extensive use of electronic systems for this task. The FAA has an extended project to develop a Central Weather Processor (CWP) to improve the collection, synthesis and dissemination of weather information throughout the National Airspace System to pilots, controllers, traffic management specialists/coordinators and meteorologists [8]. Under this project, meteorologists located at certain control units will have automated work stations which will greatly help them analyze evolving and potentially hazardous weather conditions, and provide accurate and current information to all system users. The CWP has two major parts. The first is a Meteorologist Weather Processor (MWP), which will be a computerbased interactive meteorological data processing source, providing modern automation support for weather analysis and forecasting functions. The second part is a Real-time Weather Processor (RWP), which will mosaic data from multiple WSR-88D radars, and provide these products and other important weather information to air traffic controllers 
via an Advanced Automation System (AAS). A Data Link Processor will transmit a subset of the RWP products to pilots via the Mode $\mathrm{S}$ data link, which will be fully operational by the year 2000 .

Notwithstanding the very high level of automation envisaged in the modern aviation weather surveillance systems, the decisions regarding flight will remain essentially centered on the pilots and, to a certain extent, on the controllers. In fact, more will be demanded of them by way of assimilation of diverse meteorological information inputs and dynamic decision making. The FAA and other agencies are planning training aids and educational packages [192] [193] to help them in these tasks.

In synthesizing aviation weather information from the large number of sources that will become available during the nineties, it must be remembered that, although many of the weather instrumentation systems have a varying degree of overlap in their functions, they also have significant differences in their characteristics and coverage. It must also be remembered that optimal utilization of these sources would depend strongly on the size and location of the airport, traffic densities and patterns, the type of aviation activity involved, and the location of the weather instrumentation in relation to the airport. Airports range in activity levels from the very busy ones such as those at Chicago and Atlanta, with hundreds of thousands of commercial airliner departures per year, to small community airports primarily serving general aviation and recreational needs. Obviously, the type and number of weather instrumentation systems they can support and efficiently utilize will be very different for different airports.

The airports at the upper end of the scale have enough aviation activity and economic importance to justify most of the dedicated systems discussed in this paper, and are planned to have them within the next decade. The WSR$88 \mathrm{D}$ network is so planned that many of these airports will have a WSR-88D system closely located. In addition, these airports will have dedicated TDWR's at 10-12 km from the runway complex, and each will have an ASR9 and LLWAS located within the airport area. Further, they will also have AWOS/ASOS and perhaps one or more wind profilers. The WSR-88D, TDWR, and ASR9 will provide considerable overlap in the detection and characterization of precipitation and wind fields over the terminal area. These three radars, in that order, will have increasing rates of data update, minimizing the chances of missing rapidly developing and decaying phenomena. In addition to these radars, wind shift data over airports will also come from the LLWAS. Together, these systems will enhance the reliability of the detection of weather phenomena by providing backup facilities in the event of failure of one or more of the systems. However, when all the systems function normally, it will be necessary to optimally utilize their data to enhance the detection of hazardous features and minimize possible conflicts between these data sources.

Airports that are not in the top category will, in general, have WSR-88D's located farther from them, and will not have data from this source that meets the terminal area observation criteria. At such airports, the primary instrument for wind field observation will be the TDWR, with very limited backup information from an extended (with 12 or more wind sensors) LLWAS. The TDWR and the ASR-9 will have overlapping capabilities in precipitation detection and categorization over the runway complex and its vicinity. In airports that will not have even the TDWR, the ASR-9 weather channel will be the primary sensor for precipitation-bearing weather phenomena, and the optional Doppler processor for the ASR-9 can provide information on wind fields. The ASR-9 weather channel, however, does not have good clear-air observation capability and hence the LLWAS will be the primary source of information on wind changes under such conditions, which include gust fronts, dry microbursts, etc.

At airports that will not have any dedicated radar, the LLWAS will be the chief source of wind field information. Locating the peripheral wind sensors a few kilometers out into the approach directions of aircraft will provide a degree of warning regarding the vulnerability of aircraft to wind shifts during the critical landing and takeoff phases, and close spacing of the sensors will provide the capability of microburst detection. Thus in the absence of any dedicated radar, a higher level configuration of the LLWAS (i.e., one with a larger number of sensors) may be necessary. In addition, a relatively inexpensive boundary layer profiler could be located at the airport to provide low altitude vertical wind shear data that are highly useful for the landing and takeoff operations.

All classes of airports will have continuously available data from the AWOS/ASOS. At very small airports, where the main activity is general aviation, and which will not have either the dedicated radars or the LLWAS, the only dedicated source of timely weather information will be the AWOS/ASOS. Because these systems will provide more accurate and current data than the present manually operated sources, which will be available automatically round the clock, their widespread installation will mark a distinct advance in the quality of weather information service available to general aviation pilots. The FAA expects [8] over 1100 of these systems to be installed in the U.S. by the year 2000; thus the availability of these systems will be widespread throughout the U.S. These data, combined with improved local forecast and observational data resulting from the use of the new generation of satellites, and WSR-88D data, even at a distance, hold the promise of significantly improving the safety of general aviation, which is a fast-expanding sector of aviation activity in the U.S.

\section{DiRections of FutURE ACTIVITY}

The rapid developments in the U.S. aviation weather scene are a part of the overall National Airspace Plan which is laid out till the end of the 1990's. Thus most of the nearterm developments are those that are driven by this plan and essentially consist of completing the ongoing technical development of the hardware and software, validating them 
through repeated and controlled tests, and installing them at designated locations. However, beyond this phase, it is possible to look at directions which are of scientific interest, and are likely to yield dividends in future in the particular context of aviation weather. In this section, a few such areas are identified.

Given that aviation weather information is heavily based on nowcasting, the efficacy of this information will be greatly enhanced by improving its predictive components. As aviation may be most profoundly affected by phenomena whose perceptible effects develop in a matter of minutes, improving their warning time by even a few minutes would significantly enhance the possibility of averting their disastrous or disrupting effects. Here, we refer not to environments such as thunderstorms or squall lines, but individual features such as microbursts, tornadoes, gust fronts, etc. Unfortunately, their small spatial and temporal scales and sudden onset make these phenomena highly unpredictable, but it is possible that precursor signatures exist that could be used to forewarn of the occurrence of these phenomena. Precursor signatures for local phenomena, which may consist of faint and diffuse changes in ambient or upper-layer temperature, reflectivity, circulation and other parameters, are an active area of research (e.g., [194], [195]). Artificial intelligence techniques are being developed for the identification of these signatures [196], [197].

Another direction in which weather instrumentation, in particular coherent weather radar technology, has been advancing in recent years, is the use of polarization diversity for studying microphysical processes in clouds and characterization of precipitation fields. By transmitting and/or receiving radar signals polarized in two orthogonal directions, it is possible to obtain finer information regarding the composition of precipitation fields than is possible with the single-polarization (Doppler or conventional) radar. By measuring the differential amplitude and the differential phase between signals with two polarizations, it is possible to estimate rainfall intensities more accurately, and to identify the occurrence of microphysical processes such as regions of melting of ice particles in thunderstorms [198], [199]. To the extent that atmospheric phenomena are often accompanied or preceded by changes at the microphysical level, the finer observation of microphysical processes may improve our ability to discern precursor signatures of certain hazardous phenomena. For example, the observation of the transport of large drops above the freezing level, which is done more advantageously by dual-polarization radars, may serve to provide advance warning of the onset of downbursts [200]. By utilizing different decision criteria, it appears possible to declare the existence of hail at a given point in a thunderstorm and even estimate its size distribution [201]-[203]. With further refinement of the dual-polarization technique and increase in the confidence level of decision, such knowledge would be helpful for air navigation en route as well as in terminal areas. This subject is currently an area of active research. The WSR-88D system has been designed to accept additional circuitry for polarization diversity as an option, but such additions are not part of the configuration the network radars.

\section{CONCLUding REMARKS}

A summary of the motivation, evolution, status, and directions of evolution regarding the instruments and systems dedicated, or contributing in a major way, to the enhancement of the safety, comfort, economy and efficiency of air travel has been provided in this paper. Much of the developments in this area has been due to a combination of better insight into local severe weather processes and their interaction with aircraft. The increase in size and sophistication of aircraft, with the attendant high cost of air accidents, has also been a motivating factor. The evolution of the modern aviation weather system has further been aided greatly by technological developments during the recent decades. Of particular significance are those concerning Doppler weather radars, and affordable computational hardware and software to perform high-volume processing, as well as intelligent functions.

During the process of development of the aviation weather system, the Doppler weather radar has emerged as the key instrument. Its coverage, resolution, and data update rates most nearly match the needs of aviation operations, and it is capable of detecting, characterizing, and estimating the severity of atmospheric air motion, which is most detrimental to aircraft flight. The high potential of the Doppler radar in alleviating weatherrelated aviation hazards and impediments has spawned the simultaneous development of three major systems of this class: WSR-88D, TDWR, and ASR-9 weather channel with Doppler capability.

In addition to these major systems, a number of medium and small (in cost and complexity) instrument systems have been developed for aviation support. These include the LLWAS, profiler radars, and the AWOS/ASOS. These systems will not provide as complete a picture of the weather environment as a radar, but their higher affordability will permit installation in large numbers, covering even small airports with predominantly general aviation activity. Within the decade, all these dedicated instruments, together with conventional weather data sources, will provide to pilots and controllers a weather picture of the aviation environment with a much higher degree of completeness, accuracy and timeliness than has been hitherto available. However, these multiple, and often overlapping, data fields must be properly synthesized for optimum cost-benefit to justify the investments made in this area.

A clear and conscious direction of growth for the aviation weather system has been toward the increasing use of automation both in the operation of instruments and systems, and in the processing, interpretation, communication, and display of the high-quality data obtained by the instruments. In particular, a high level of emphasis has been laid on the use of intelligent algorithms for automatic recognition of atmospheric features that are potentially hazardous to aviation. Many such algorithms have been developed and 
tested for the three radar systems as well as the LLWAS. This approach has the advantage of reducing costs by involving less human effort, and being more objective, vigilant, and agile than human operators. However, they have the drawback of not being able to directly utilize human experience and the superior cognitive abilities of human perception. On the balance, highly automated operation of the instruments and networks, with limited human involvement at nodal locations, appears to be the best way to manage large weather observation systems and networks involving high volumes of data, while still maintaining a high degree of currency of the information such as is required for aviation operations. Progress toward automation in this area is also in step with other segments of aviation instrumentation, such as navigation, communication, etc., which are undergoing substantial automation themselves, as a part of the National Airspace Plan.

The aviation weather surveillance and management system, complex and comprehensive as it is, is only a part of the overall plan for improving all aspects of aviation operations. When the plan is largely implemented by the year 2000 , the resulting system is expected to effectively service the aviation community well into the twenty first century.

\section{ACKNOWLEDGMENT}

This work was done while the first author, Dr. P. R. Mahapatra, held a National Research Council-National Oceanic and Atmospheric Administration Senior Research Associateship. The authors acknowledge the support provided by Dr. R. A. Maddox, Director of the National Severe Storms Laboratory. Laurie Hermes furnished useful information on gust front detection statistics for TDWR. Discussions with D. Burgess, M. Eilts, and D. Doviak have helped clarify certain points. D. Forsyth and M. Eilts have reviewed the manuscript and suggested improvements. Joan Kimpel has drafted the line diagrams used in the illustrations. The continued sponsorship of the FAA has generated a diversified background of aviation weather related research at the National Severe Storms Laboratory, which this paper has drawn upon liberally.

\section{REFERENCES}

[1] M. A. Fischetti, "New times at the FAA," IEEE Spectrum, vol. 23 , no. 11 , pp. $67-69$, Nov. 1986

[2] U.S. Dep. of Transportation, "Air traffic control," Federal Aviation Administration Rep. 7110.65 F, Sept. 21, 1989.

[3] T. S. Perry and P. Wallich, "A matter of margins," IEEE Spectrum, vol. 23 , no. 11 , pp. $38-49$, Nov. 1986.

[4] G. B. Litchford, "Avoiding mid-air collision," IEEE Spectrum, vol. 12, no. 9, pp. 41-48, Sept. 1975.

[5] M. A. Fischetti and T. S. Perry, "Our burdened skies," IEEE Spectrum, vol. 23 , no. 11 , pp. 36-37, Nov. 1986.

[6] National Academy of Sciences, Low Altitude Wind Shear and its Hazard to Aviation. Washington, DC: National Academy Press, 1983.

[7] U.S. Dep. of Transportation, "National airspace systems plan," Federal Aviation Administration, Dec. 1981

[8] __. "National airspace systems plan: Facilities, equipment, associated development and other capital needs," Federal Aviation Administration Rep., Sept. 1989.
[9] J. McCarthy, Ed., Aviation Weather Forecasting Task Force Final Report. Boulder, CO: National Center for Atmospheric Res., 1986.

[10] A. L. Hansen, "Ground based weather radar for aviation," in Proc. Third Int. Conf. on Aviation Weather System, Anaheim, CA, pp. 420-421, 1989.

[11] R. D. Rudich, "Weather-involved U.S. air carrier accidents 1962-1984: A compendium and brief summary," in Proc AIAA 24th Aerospace Sciences Mtg., Reno, NV, Paper AIAA86-0327, 1986.

[12] E. Bromley, Jr., "Aeronautical meteorology: Progress and challenges-Today and tomorrow," Bull. Amer. Meteorol. Soc., vol. 58 , pp. $1156-1160,1977$.

[13] PROFS, "Report of a study to estimate economic and convenience benefits of improved local weather forecasts," NOAA Tech. Memo. ERL-PROFS-1, 1979.

[14] R. J. Serafin, "Nowcasting and Aviation Safety," in Proc. Workshop on Multiparameter, Doppler Weather Radar for India, Bangalore, India, pp. 15-19, 1986.

[15] E. Kessler, "Use, nonuse, and abuse of weather radar," J. Aircraft, vol. 25, pp. 448-452, 1988.

[16] "On Low-Level Windshear Alert Systems (LLWAS) and Doppler radar in aircraft terminal operations," J. Aircraft, vol. 27, pp. 423-428, 1990.

[17] K. A. Browning, Ed., Nowcasting. London, UK: Academic, 1982, p. ix.

[18] E. Kessler "Wind shear and aviation safety," Nature, vol. 315, pp. 179-180, May 16, 1985.

[19] P. R. Mahapatra, R. J. Doviak, and D. S. Zrnic', " Radar detection of low level wind shear affecting aircraft terminal navigation," in Proc. Nat. Aerosp. Mtg., of Inst. of Navigation, Moffett Field, CA, pp. 52-59, 1982.

[20] O. Stewart, Danger in the Air. London, UK: Philosophical Library, 1958, pp. 59-62.

[21] P. E. Viemeister, The Lightning Book. New York: Doubleday, 1961.

[22] M. Swolinsky, "Wind shear models for aircraft hazard investigation," in Proc. 2nd Int. Symp. on Aviation Safety, Toulouse, France, Nov. 1986 (published by Cepad, Toulouse) pp. $101-122,1988$.

[23] W. Frost and D. W. Camp, "Wind shear modeling for aircraft hazard definition," Federal Aviation Administration Rep. FAARD-77-36, 1977

[24] R. Brockhaus, "A global model of the coupled process of aircraft motion and wind field," in Proc. 2nd Int. Symp. on Aviation Safety, Toulouse, France, Nov. 1986 (published by Cepad, Toulouse), pp. 123-137, 1988.

[25] National Transportation Safety Board, "Skyways International, Inc., Douglas DC-7C, N296 near the Miami International Airport, Dade County, Florida, June 21, 1973," Rep. NTSB AAR74-2, 1974.

[26] _ "Pan American World Airways, Inc., Boeing 747-121, N739PA near Nantucket, Massachusetts, November 4, 1970," Rep. NTSB AAR-72-14, 1972

[27] "National Airlines, Inc., Boeing 747-135, N77772 near Lake Charles, Louisiana, January 4, 1972," Rep. NTSB AAR$72-21,1972$

[28] _ , "Northwest Airlines, Inc., Boeing 747-151, N606US over the North Pacific Ocean 105 Nautical Miles West of $150^{\circ}$ East Longitude at $36^{\circ}$ North Latitude, April 12, 1972," Rep. NTSB AAR-72-27, 1972

[29] _ "Air France Boeing 707B-328B, F-BLCA near O'Neill, Nebraska, May 13, 1974," Rep. NTSB AAR-75-4, 1975.

[30] "Braniff Airways, Inc., BAC 1-11, N1553 near Falls City, Nebraska, August 6, 1966," Docket SA 393, 1967.

[31] "Wien Consolidated Airlines, Inc., Fairchild F-27B N4905, Pedro Bay, Alaska, December 2, 1968," Rep. NTSB AAR-70-16, 1970

[32] _ " "Southern Airways, Inc., Douglas DC-9-31, N1335U, New Hope, Georgia, April 4, 1977," Rep. NTSB AAR-78-3, 1978.

[33] _ "Air Wisconsin, Inc., Swearingen SA-226 Metro, N650S Valley, Nebraska, June 12, 1980," Rep. NTSB AAR-80-15, 1980.

[34] P. A. Haines and J. K. Luers, "Aerodynamic penalties of heavy rain on landing airplanes," J. Aircraft, vol. 20, pp. 111-119, 1983.

[35] J. K. Luers and P. A. Haines, "Experimental measurements of 
rain effects on aircraft aerodynamics," AIAA Paper 83-0275, Jan. 1983.

[36] E. H. Phillips, "NASA will study heavy rain effects on wing aerodynamics," Aviation Week and Space Technol., vol. 130, no. 7, pp. 38-41, Feb 13, 1989.

[37] M. A. Dietenberger, P. A. Haines, and J. K. Luers, "Reconstruction of Pan Am New Orleans accident," J. Aircraft, vol. 22, pp. $719-728,1985$.

[38] National Transportation Safety Board, "Pan American World Airways Clipper 759, N4737, Boeing 727-235, New Orleans International Airport, Kenner, Louisiana, July 9, 1982," Rep. NTSB AAR-83-02, 1983.

[39] G. A. Beals, "Rain models for landing guidance systems," U.S. Air Force Rep. USAF ETAC TN 69-9, Nov. 1969.

[40] National Transportation Safety Board, "Redcoat Air Cargo Ltd,, Bristol Britannia 253F, G-BRAC, Billerica, Massachusetts, February 16, 1980," Rep. NTSB AAR-81-3, 1981.

[41] R. J. Hansman, Jr., "The influence of ice accretion physics on the forecasting of aircraft icing conditions," in Proc. Third Int. Conf. on the Aviation Weather System, pp. 154-158, 1989.

[42] W. A. Cooper, W. R. Sand, M. K. Politovich, and D. L. Veal, "Effects of icing in performance of a research aircraft," $J$. Aircraft, vol. 21, pp. 708-715, 1984.

[43] M. K. Politovich, "Aircraft icing caused by large supercooled droplets," J. Appl. Meteor., vol. 28, pp. 856-858, 1989.

[44] W. R. Sand, M. K. Politovich, and R. M. Rasmussen, "A program to improve aircraft icing forecasts," in Proc. AIAA 28th Aerospace Sciences Mtg., Reno, NV, Paper No. AIAA-90-0196, 1990.

[45] Civil Aeronautics Board, "Lockheed Electra L-188, N6102A, American Airlines, Inc., Municipal Airport, Kansas City, Missouri, January 29, 1963," CAB File No. 1-0018, 1963.

[46] C-54B-DC, N384, Castle Island, Boston, Massachusetts, March 10, 1964," CAB File No. 1-003, 1964.

[47] National Transportation Safety Board, "Rocky Mountain Airways, Inc., De Havilland DHC-6 Twin Otter, N25RM near Steamboat Springs, Colorado, December 4, 1978," Rep. NTSB AAR-79- 6, 1979.

[48] L. Czekalski, "Overview of FAA's aircraft icing programs," in Proc. 7th Annual NASA Workshop, pp. 30-34, 1983.

[49] P. Huffman and P. A. Haines, "Visibility in heavy precipitation and its use in diagnosing high rainfall rates," AIAA Paper 84-0541, Jan 1984

[50] V. Mazur, D. B. Fisher and J. C. Gerlach, "Lightning strikes to an airplane in a thunderstorm," J. Aircraft, vol. 21, pp.607-611, 1984

[51] D. R. Fitzgerald, "Probable aircraft triggering of lightning in certain thunderstorms," Monthly Weather Rev., vol. 95, pp. $835-842,1967$.

[52] V. Mazur, D. B. Fisher, and J. C. Gerlach, "Lightning strikes to a NASA airplane penetrating thunderstorms at low altitudes," J. Aircraft, vol. 23, pp. 499-505, 1986

[53] Civil Aeronautics Board, "Boeing 707-121, N709PA, Pan American World Airways, Inc., near Elkton, Maryland, December 8, 1963," CAB File No. 1-0015, 1964.

[54] U.S. Department of Transportation, "Windshear training aid," prepared for FAA under Contract No. DTFA01-86-C-00005 by the Boeing Co., Lockheed Corp., United Airlines, American Weather Assoc. Inc., and Helliwell, Inc., 1987

[55] L. J. Battan, The Nature of Violent Storms. New York: Doubleday, 1961 , ch. 4

[56] C. Magono, Thunderstorms. Amsterdam, The Netherlands: Elsevier, 1980, ch. 1.

[57] P. S. Ray, "Convective dynamics," in Radar in Meteorology, D. Atlas, Ed., Boston, MA: Amer. Meteorol. Soc., 1990, ch. $24 a$, pp. $348-390$.

[58] D. W. Burgess and L. R. Lemon, "Severe thunderstorm detection by radar," in Radar in Meteorology, D. Atlas, Ed., Boston, MA: Amer. Meteorol. Soc., 1990, ch. 30a, pp. 619-647.

[59] National Transportation Safety Board, "Ozark Airlines, Inc. Fairchild Hiller FH-227B, N421S near the Lambert-St. Louis International Airport, St. Louis, Missouri, July 23, 1973,” Rep. NTSB AAR-74-5, 1974.

[60] $\longrightarrow$ "Delta Air Lines, Inc., McDonnell Douglas DC-9-32, N3323L, Chattanooga Municipal Airport, Chattanooga, Tennessee, November 27, 1973," Rep. NTSB AAR-74-13, 1974.

[61] __ , "Iberia Lineas Aereas de Espana (Iberian Airlines) Mc-
Donnell Douglas DC-10-30 EC-CBN, Logan International Airport, Boston, Massachusetts, December 17, 1973," Rep. NTSB AAR-74-14, 1974.

[62] _ "Pan American World Airways, Inc., Boeing 707-321B, N454PA, Pago Pago, American Samoa, January 30, 1974," Rep. NTSB AAR-77-7 (revised), 1977.

[63] "Eastern Airlines, Inc., Boeing 727-225, N8845E, John F. Kennedy International Airport, Jamaica, New York, June 24, 1975," Rep. NTSB AAR-76-8, 1976.

[64] , "Eastern Airlines, Inc., Boeing 727, N8838E, Raleigh, North Carolina, November 12, 1975," Rep. NTSB AAR-83/06, 1983.

[65] Philadelphia, Pennsylvania, June 23, 1976," Rep. NTSB AAR$78-2,1978$

[66] , "U.S.Air, Inc., Flight 183, McDonnel Douglas DC-9-31, N964VJ, Detroit Metropolitan Airport, Detroit, Michigan, June 13, 1984, Rep. NTSB AAR-85/01, 1985.

[67] _ "Continental Airlines, Inc., Boeing 727-224, N88777,

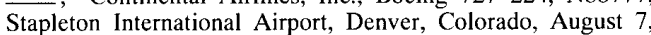
1965," Rep. NTSB AAR-76-14, 1976.

[68] _ "Continental Air Lines, Inc., Boeing 727-224, N32725, Tucson, Arizona, June 3, 1977," Rep. NTSB AAR-78-9, 1978

[69] T. T. Fujita, The Downburst. Chicago, IL: The University of Chicago, 1985.

[70] "Spearhead echo and downburst near the approach end of John F. Kennedy Airport runway, New York City," SMRP Res. Paper 137, Univ. of Chicago, 1976.

[71] T. T. Fujita and H. R. Byers, "Spearhead echo and downbursts in the crash of an airliner," Mon. Wea. Rev., vol. 105, pp. $129-146,1977$

[72] T. T. Fujita and F. Caracena, "An analysis of three weatherrelated aircraft accidents," Bull. Amer. Meteorol. Soc., vol. 58, pp. $1164-1181,1977$

[73] T. T. Fujita, "Microburst wind shear at New Orleans International Airport, Kenner, Louisiana on July 9, 1982," SMRP Res. Paper 199, University of Chicago, 1983.

[74] _ DFW Microburst. Chicago, IL: The Univ. of Chicago, 1986.

[75] _ "Microburst as an aviation wind shear hazard," AlAA Paper AIAA-81-0386, 1981

[76] J. McCarthy, "Recommendations for coping with microburst wind shear: An aviation hazard," J. Air Law and Commerce, vol. 49 , pp. $337-359,1984$.

[77] J. McCarthy and R. J. Serafin, "The microburst hazard to aircraft," Weatherwise, vol. 37, pp. 120-127, 1984.

[78] J. McCarthy and J. W. Wilson, "The microburst as a hazard to aviation," in Proc. Nowcasting -II Symp., Norrkoping, Sweden, pp. 21-30, 1984.

[79] T. T. Fujita, "Objectives, operation and results of Project NIMROD," Preprints, in 11th Conf. on Severe Local Storms, Kansas City, KS, pp. 259-266, 1979.

[80] T. T. Fujita and R. M. Wakimoto, "Microbursts in JAWS depicted by Doppler radars, PAM and aerial photographs," Preprints, in 21st Conf. on Radar Meteorology, Edmonton, Canada, pp. 638-645, 1983.

[81] M. D. Eilts and R. J. Doviak, "Oklahoma downbursts and their asymmetry," J. Climate Appl. Meteorol., vol.26, pp. 69-78, 1987.

[82] T. T. Fujita and J. McCarthy, "The application of weather radar to aviation meteorology," in Radar in Meteorology, D. Atlas, Ed., Boston, MA: Amer. Meteorol. Soc., 1990, ch. 31a, pp. $657-681$.

[83] T. T. Fujita, “Andrews AFB Microburst,” SMRP Res. Paper 205 Univ. of Chicago, 1983

[84] M. M. Wolfson, "Characteristics of microbursts in the continental United States," The Lincoln Lab. J., vol. 1, pp. 49-74 1988.

[85] R. P. Davies-Jones, "Tornado Dynamics" in Thunderstorm Morphology and Dynamics, E. Kessler, Ed. 2nd ed. Norman, OK: Univ. of Oklahoma Press, 1986, ch. 10, pp. 197-237.

[86] D. S. Zrnić, D. W. Burgess, and L. Hennington, "Doppler spectra and estimated windspeed of a violent tornado," $J$ Climate Appl. Meteorol., vol. 24, pp. 1068-1081, 1985.

[87] T. T. Fujita, U.S. Tornadoes. Chicago, IL:The Univ, of Chicago, 1987.

[88] J. McCarthy, E. F. Blick, and K. Elmore, "An airport wind shear detection and warning system using Doppler radar," Rep. NASA CR 3379, 1981.

PROCEEDINGS OF THE IEEE, VOL. 79, NO. 9, SEPTEMBER 1991 
[89] Y. K. Sasaki and T. L. Baxter, "The gust front," in Thunderstorm Morphology and Dynamics, E. Kessler, Ed., 2nd ed. Norman, OK: Univ of Oklahoma Press, 1986, ch. 9, p. 187.

[90] F. H. Ludlam, Clouds and Storms. The Behavior and Effect of Water in the Atmosphere. University Park, PA: The Pennsylvania State Univ., 1980, ch. 8, pp. 270-281.

[91] Federal Aviation Administration Academy, Weather and Flying Safety Chapter 6: Thunderstorms. FAA Mike Monroney Aeronautical Center, Nov, 1981.

[92] National Transportation Safety Board, "Air Florida, Boeing 737, Washington, D.C. National Airport, January 1982,” Rep. NTSB AAR-82-8, 1982.

[93] R. B. Stull, An Introduction to Boundary Layer Meteorology. Dordrecht, The Netherlands: Kluwer Academic, 1988, ch. 1, p. 15.

[94] E. Kessler, "Survey of boundary layer winds with special reference to extreme values," in Proc. AlAA 7th Fluid and Plasma Dynamics Conf., Palo Alto, CA, Paper 74-586, 1974.

[95] R. Konig, P. Krauspe, and G. Schanzer, "Procedures to improve flight safety in wind shear conditions," in Proc. 12th Congress of the Int. Council of the Aeronautical Sciences, Munich, FRG, pp. 744-757, 1980

[96] D. R. Christie and K. J. Muirhead, "Solitary waves: A hazard to aircraft operating at low altitudes," Australian Meteor. Mag. vol. 31, pp. 97-109, 1983.

[97] R. J. Doviak and D. R. Christie, "Thunderstorm-generated solitary waves: A wind shear hazard," $J$. Aircraft, vol. 26, pp. $423-431,1989$

[98] R. J. Doviak and S. Chen, "Observations of a thunderstormgenerated gust compared with solitary wave theory," Federal Aviation Administration Rep. DOT/FAA/SA-88/1, 1988.

[99] U.S. Dep. of Transportation, "The Federal Aviation Administration plan for research, engineering and development, Volume II: Project descriptions," Federal Aviation Administration, Jan. 1989.

[100] P. R. Mahapatra and D. S. Zrnić, "Lifetimes of convective atmospheric phenomena hazardous to aviation: A study with ap plication to the design of scan strategies for NEXRAD," Federal Aviation Administration Rep. DOT/FAA/RD-82/69, July 1982

[101] M. R. Hjelmfelt, "Structure and life cycle of microburst outflows observed in Colorado," J. Appl. Meteorol., vol. 27, no. 8, pp. 900-927, 1988

[102] J. McCarthy, "Advances in weather technology for the aviation system," Proc. IEEE, vol. 77, pp. 1728-1734, 1989

[103] U.S. Dep. of Transportation, "Terminal area weather radar detection and convective prediction development," Interagency Agreement DTFA01-81-Y-10521 between DoT/FAA and DoC/NOAA, Jan. 7, 1981

[104] R. J. Doviak, D. S. Zrnić and D. S. Sirmans, "Doppler weather radar," Proc. IEEE, vol. 67, pp. 1522-1553, 1979.

105] R. J. Doviak and D. S. Zrnić, Doppler Radar and Weather Observations. Orlando, FL: Academic, 1984

[106] M. J. Istok, "An analysis of the relation between Doppler spectrum width and thunderstorm turbulence," M.S. thesis, Univ. of Oklahoma, 1983

[107] J. T. Lee, "Applications of Doppler weather radar to turbulence measurements which affect aircraft," Federal Aviation Administration Rep. FAA-TF-77-145, 1977.

[108] A. R. Bohne, "Radar detection of turbulence in precipitation environments," J. Atmos. Sci., vol. 39, pp. 1819-1837, 1982.

[109] D. S. Zrnić and J. T. Lee, "Pulsed Doppler radar detects weather hazards to aviation," J. Aircraft, vol. 19, pp. 183-190, 1982.

[110] D. S. Zrnić "Estimation of spectral moments for weather echoes," IEEE Trans. Geosci. Electron.,vol. GE-17, pp. $113-128,1979$

[111] _ "Spectral moment estimates from correlated pulse pairs," IEEE Trans. Aerosp. Electron. Syst., vol. AES-13, pp. 344-354, 1977.

[112] P. R. Mahapatra and D. S. Zrnić, "Practical algorithms for mean velocity estimation in pulse Doppler weather radars using a small number of samples," IEEE Trans. Geosci. Remote Sens., vol. GE-21, pp. 491-501, 1983.

[113] D. S. Zrnić and P. R. Mahapatra, "Two methods of ambiguity resolution in pulse-Doppler weather radars," IEEE Trans. Aerosp. Electron. Syst., vol. AES-21, pp. 470-483, 1985.

[114] M. Sachidananda and D. S. Zrnic, "Recovery of Spectral Moments from overlaid echoes in a Doppler weather radar," IEEE Trans. Geosci. Remote Sens., vol. GE-24, pp. 751-764,
1986

[115] M. D. Eilts and S. D. Smith, "Efficient dealiasing of Doppler velocities using local environment constraints," J. Atmos. Ocean. Tech., vol. 7, pp. 118-128, 1990.

[116] R. M. Lhermitte, "Dual Doppler radar observations of convective storm circulation," in Proc. 14th Radar Meteorol. Conf., Tucson, AZ, Amer. Meteorol. Soc., pp. 139-144, 1970.

[117] L. Armijo, "A theory for the determination of wind and precipitation velocities with Doppler radars," J. Atmos. Sci., vol. 26, pp. $570-573,1969$

[118] D. S. Zrnić and P. R. Mahapatra, "Automatic recognition and feature extraction of atmospheric convective processes from single Doppler radar observations," in Proc. 1989 Int. Symp. on Noise and Clutter Rejection in Radars and Imaging Sensors (ISNCR-89), Kyoto, Japan, pp. 347-352, 1989.

[119] C. J. Bjerkaas and D. E. Forsyth, "An automated real-time storm analysis and storm tracking program (WEATRK)," Air Force Geophysics Lab. Rep. AFGL-TR-80-0316, 1980.

[120] R. E. Rinehart and E. T. Garvey, "Three-dimensional storm motion detection by conventional weather radar," Nature, vol. 273 , pp. $287-288,1978$.

[121] A. Bellon and G. L. Austin, "The evaluation of two years of real-time operational short-term precipitation forecasting procedure (SHARP)," J. Appl. Meteorol., vol. 17, pp. 1778-1787, 1978.

[122] G. R. Smythe and D. S. Zrnić, "Correlation analysis of Doppler radar data and retrieval of the horizontal wind," J. Clim. Appl. Meteorol., vol. 22, pp. 297-311, 1983.

[123] R. K. Crane, "Automatic cell detection and tracking," IEEE Trans. Geosci. Electron., vol. GE-17, pp. 250-262, 1979.

[124] C. J. Bjerkaas and D. E. Forsyth, "Operational test of a three-dimensional echo tracking program," in Proc. 19th Radar Meteorol. Conf., Miami Beach, FL, pp. 244-247, 1980.

[125] D. S. Zrnić, D. W. Burgess, and L. D. Hennington, "Automatic detection of mesocyclonic shear with Doppler radar," J. Atmos. Ocean. Tech., vol. 2, pp. 425-438, 1985.

[126] D. S. Zrnić and Y. Gal-Chen, "Divergence measurement in storm tops," Report for the Joint Systems Program Office, NSSL, Norman, OK, 1983.

[127] R. Eyster, "Storm top divergence from single Doppler velocity fields and its relationship to storm intensification and severity," CIMMS Rep. 70, Univ. of Oklahoma, 1986.

[128] M. W. Merritt, "Microburst divergence detection for Terminal Doppler Weather Radar," in Proc. 24th Conf. on Radar Meteorology, Tallahassee, FL, pp. 220-223, 1989.

[129] H. Uyeda and D. S. Zrnić, "Automatic detection of gust fronts," J. Atmos. Ocean. Tech., vol. 3, pp. 36-50, 1986.

[130] S. D. Smith, A. Witt, M. D. Eilts, L. G. Hermes, D. KlingleWilson, S. H. Olson, and J. P. Sanford, "Gust front detection algorithm for the Terminal Doppler Weather Radar, Part I Current status," in Proc. Third Int. Conf. on the Aviation Weather System, Anaheim, CA, pp. 31-34, 1989.

[131] S. Olson, "Overview of an artificial intelligence system for gust front recognition and tracking," Preprints in 23rd Conf. on Radar Meteorol., Amer. Meteorol. Soc., pp. 22-25, 1986.

[132] S. D. Campbell and S. H. Olson, "Recognizing low-altitude wind shear hazards from Doppler weather radar: An artificial intelligence approach,"J. Atmos. Ocean. Tech., vol. 4, pp. 5-18, 1987.

[133] R. C. McArthur, J. C. Davis, and D. Reynolds, "Scenario-driven automatic pattern recognition in nowcasting," J. Atmos. Ocean. Tech.,vol. 4, pp. 29-35, 1987.

[134] P. R. Mahapatra and J. T. Lee, "The role of NEXRAD in aircraf navigation and flight safety enhancement," Navigation, vol. 31 pp. $21-37,1984$

[135] UNISYS, "NEXRAD," Introductory Brochure, Undated.

[136] W. H. Heiss, D. L. McGrew, and D. S. Sirmans, "Nexrad: Next generation weather radar (WSR-88D)," Microwave J., vol. 33, no. 1 , pp. $79-98,1990$

[137] P. R. Mahapatra, D. S. Zrnić and R. J. Doviak, "Optimum siting of NEXRAD to detect hazardous weather at airports," J. Aircraft, vol. 20 , pp. $363-371,1983$.

[138] D. Turnbull, J. McCarthy, J. Evans, and D. S. Zrnić, "The FAA terminal Doppler weather radar (TDWR) program," in Proc. Third Int'l Conf. on the Aviation Weather System, Anaheim, CA, pp. 414-419, 1989.

[139] J. W. Wilson, R. D. Roberts, C. Kessinger, and J. McCarthy, "Microburst wind structure and evaluation of Doppler radar for 
airport wind shear detection," J. Clim. Appl. Meteorol., vol. 23, pp. $898-915,1984$

[140] M. Michelson, W. W. Shrader, and J. G. Wieler, "Terminal Doppler weather radar," Microwave J., vol. 33, pp. 139-148. 1990.

[141] Raytheon Co., "Terminal Doppler weather radar (TDWR)," Introductory Leaflet, Undated.

[142] J. Evans and D. Turnbull, "Development of an automated windshear detection system using Doppler weather radar," Proc. IEEE, vol. 77, pp. $1661-1673,1989$.

[143] R. H. Allen, D. W. Burgess, and R. J. Donaldson," Attenuation problems associated with a $5-\mathrm{cm}$ radar," Bull. Amer. Meteorol. Soc., vol. 62, pp. 807-810, 1981 .

[144] S. H. Lin, "A method for calculating rain attenuation distributions on microwave paths," Bell Syst. Tech. J., vol. 54, pp. $1051-1086,1975$.

[145] D. C. Hogg, "Statistics on attenuation of microwaves by intense rain," Bell Syst. Tech. J., vol. 48, pp. 2949-2962, 1969.

[146] P. H. Hildebrand, "Iterative correction for attenuation of $5 \mathrm{~cm}$ radar in rain," J. Appl. Meteorol., vol. 17, pp. 508-514, 1978.

[147] W. Hitschfeld and J. Bordan, "Errors inherent in the radar measurement of rainfall at attenuating wavelengths," J. Meteorol., vol. 11. pp. $58-67,1954$

[148] S. C. Crocker, "TDWR PRF selection criteria," Report DOT/FAA/PM-87-25, Prepared for the Federal Aviation Administration by MIT Lincoln Lab., Mar. 15, 1988.

[149] M. W. Merritt, D. Klingle-Wilson, and S. D. Campbell, "Wind shear detection with pencil-beam radars," The Lincoln Lab. J. vol. 2, pp. 483-510, 1989

[150] S. D. Campbell, "Use of features aloft in the TDWR microburst recognition algorithm," in Proc. 24th Conf. on Radar Meteorology, Tallahassee, FL, pp. 167-168, 1989.

[151] S. D. Campbell and M. A. Isaminger, "Using features aloft to improve timeliness of TDWR hazard warning," in Proc. Third Int. Conf. on the Aviation Weather System, Anaheim, CA, pp. $184-189,1989$

[152] D. C. Puzzo, S. W. Troxel, M. A. Meister, M. E. Weber and J. V. Pieronek, "ASR-9 weather channel test report," Rep. DOT/FAA/PS-89/3, Prepared for the Federal Aviation Administration by MIT Lincoln Lab., May 3, 1989.

[153] J. W. Taylor, Jr. and G. Brunins, "Design of a new Air port Surveillance Radar (ASR-9)," Proc. IEEE, vol. 73, pp. 284-289, 1985

[154] S. W. Troxel, "ASR-9 weather channel test report, Executive summary," Rep. DOT/FAA/PS-89/6. Prepared for the Federal Aviation Administration by MIT Lincoln Lab., May 3, 1989.

[155] M. E. Weber and T. A. Noyes, "Wind shear detection with airport surveillance radars," The Lincoln Lab. J., vol. 2, pp. $511-526,1989$

[156] M. B. Alexander and D. W. Camp, "Analysis of low-altitude wind speed and direction shears," J. Aircraft, vol. 22, pp. $705-712,1985$

[157] R. B. Chadwick, A. S. Frisch, and R. G. Strauch, "A feasibility study on the use of wind profilers to support space shuttle launches," NASA Contractor Rep. 3861, Dec. 1984.

[158] P. T. May and R. G. Strauch, "An examination of wind profiler signal processing algorithms," J. Atmos. Ocean. Tech., vol. 6 , pp. $731-735,1989$.

[159] D. B. Wuertz, B. L. Weber, R. G. Strauch, A. S. Frisch, C. G Little, D. A. Merritt, K. P. Moran, and D. C. Welsh, "Effects of precipitation on UHF wind profiler measurements," J. Atmos. Ocean. Tech., vol. 5, pp. 450-465, 1988.

[160] A. S. Frisch, B. L. Weber, R. G. strauch, D. A. Merritt and K. P. Moran, "The altitude coverage of the Colorado wind profilers at 50, 405 and $915 \mathrm{MHz}$," J. Atmos. Ocean. Tech., vol. 3, pp. $680-692,1986$

[161] R. G. Strauch, D. A. Merritt, K. P. Moran, P. T. May, B L. Weber, and D. A. Wuertz, "Doppler radar wind profilers for support of flight operations," J. Aircraft, vol. 26, pp. 1009-1015, 1989.

[162] R. G. Strauch, D. A. Merritt, K. P. Moran, K. B. Earnshaw, and D. van de Kamp, "The Colorado wind profiling network," J. Atmos. Ocean. Tech., vol. 1, pp. 38-49, 1984.

[163] K. P. Moran, R. G. Strauch, K. B. Earnshaw, D. A. Merritt, B. L Weber and D. B. Wuertz, "Lower tropospheric wind profiler," in Proc. 24th Conf. on Radar Meteorol., Tallahassee, FL, pp. $728-731,1989$.

[164] W. L. Ecklund, D. A. Carter, and B. B. Balsley, "A UHF wind profiler for the boundary layer: Brief description and initial results," J. Atmos. Ocean. Tech., vol. 5, pp. 432-441, 1988.

[165] R. B. Chadwick, A. S. Frisch, and R. G. Strauch, "A feasibility study on the use of wind profilers to support space shuttle launches," NASA Contractor Rep. 3861, 1984.

[166] D. S. Zrnić S. D. Smith, A. Witt, R. M. Rabin and M. Sachidananda, "Wind profiling of stormy and quiescent atmospheres with microwave radars," NOAA Tech. Memo. ERL NSSL-98, 1986.

[167] O. P. Korhonen, "Profiling winds for air traffic- an application test at Helsinki airport," in Proc. Third Int. Conf. on the Aviation Weather System, Anaheim, CA, pp. 146-147, 1989.

[168] R. G. Strauch, K. P. Moran. P. T. May, A. J. Bedard, and W L. Ecklund, "RASS temperature soundings with wind profiler radars," in Proc. 24th Conf. on Radar Meteorol., Tallahassee, FL, pp. 741-745, 1989.

[169] P. T. May, R. G. Strauch and K. P. Moran, "The altitude coverage of temperature measurements using RASS with wind profiler radars," Geophys. Res. Lett., vol. 15, pp. 1381-1384, 1988.

[170] E. R. Westwater and R. A. Kropfli, "Remote Sensing Techniques of the Wave Propagation Laboratory for the measurement of supercooled liquid water: Applications to aircraft icing," NOAA Tech. Memo. ERL WPL-163, May 1989.

[171] F. O. Guiraud, J. Howard, and D. C. Hogg, "A dual-channel microwave radiometer for the measurement of precipitable water vapor and liquid," IEEE Trans. Geosci. Electron., vol. GE-17, pp. 129-136, 1979.

[172] D. C. Hogg, F. O. Guiraud, and E. B. Burton, "Simultaneous observations of cool cloud liquid by ground-based microwave radiometry and icing of aircraft," J. Appl. Meteorol., vol. 19, pp. $893-895,1980$.

[173] B. Stankov and A. Bedard, "Atmospheric conditions producing aircraft icing on 24-25 January 1989: A case study utiliz ing combinations of surface and remote sensors," in Proc. AIAA 24th Aerospace Sciences Mtg., Reno, NV, Paper AIAA90-0197, 1990.

[174] R. C. Goff, "The Low-Level Wind Shear Alert System (LLWSAS)," Federal Aviation Administration Rep. DOT/FAA/RD 80/45, 1980.

[175] U.S. Department of Transportation, "Project implementation plan for the Low Level Windshear Alert System (LLWAS)," FAA Directive No. 6560.24, 1989.

[176] "Integrated FAA windshear program plan: Development and logistics, aviation standard and air traffic," Federal Aviation Administration, 1987.

[177] R. C. Goff and R. H. Gramzow, "The Federal Aviation Administration's Low Level Windshear Alert System: A project management perspective," in Proc. Third Int. Conf. on the Aviation Weather System, Anaheim, CA, pp. 408-413, 1989.

[178] K. D. Jaffe, "Improvement of the performance of sensors in the Low-Level Wind Shear Alert System (LLWAS)," in Proc. Third Int. Conf. on the Aviation Weather System, Anaheim, CA, pp. 356-361, 1989

[179] G. R. Smythe, "Evaluation of the 12-station enhanced LowLevel Wind Shear Alert System (LLWAS) at Denver Stapleton International Airport," in Proc. Third Int. Conf. on the Aviation Weather System, Anaheim, CA, pp. 41-46, 1989.

[180] M. D. Eilts, "Low altitude wind shear detection with Doppler radar," J. Climate and Appl. Meteorol., vol. 26, pp. 96-106, 1987.

[181] D. McLean, "Airborne detection of wind shear," in Proc. 2nd Int. Symp. on Aviation Safety, Toulouse, France, Nov. 1986 (published by Cepad, Toulouse), pp. 227-244, 1988.

[182] K. Kraus and L. Mayou, "Impact of automated weather observing systems on aviation," in Proc. Third Int. Conf. on Aviation Weather System, Anaheim, CA, pp. 108-111, 1989.

[183] B. Hellroth and E. Olsson, "MET 90, a project for the development of the future Swedish aviation weather system," in Proc. Third Int. Conf. on Aviation Weather System, Anaheim, CA, pp. $228-232,1989$

[184] R. A. Maddox, "Mesoscale convective complexes," Bull. Amer. Meteorol. Soc., vol. 61, pp. 1374-1387, 1980.

[185] $\_$, "Satellite depiction of the life cycle of a mesoscale convective complex," Mon. Wea. Rev., vol. 109, pp. 1583-1586, 1981.

[186] J. F. W. Purdom, "Satellite observations of convection and severe storms," in Program, GOES I-M Operational Satellite

PROCEEDINGS OF THE IEEE, VOL. 79, NO. 9, SEPTEMBER 1991 
Conf., Arlington, VA, pp. 256-273, 1989.

[187] C. O. Erickson and L. F. Whitney, "Gravity waves following severe thunderstorms," Mon. Wea. Rev., vol. 101, pp. 708-711, 1973.

[188] G. Ellrod, "Dallas microburst storm environmental conditions determined from satellite soundings," in Proc. Third Int. Conf. on the Aviation Weather System, Anaheim, CA, pp. 15-20, 1989.

[189] D. L. Birkenheuer, "Use of GOES data for local forecasting," in Program, GOES I-M Operational Satellite Conf., Arlington, VA, pp 70-75, 1989

[190] F. R. Mosher, "Application of geostationary satellite data, Uses of geostationary satellite data: Past, present and future, Severe local storms," in Program, GOES I-M Operational Satellite Conf., Arlington, VA, pp. 225-228, 1989.

[191] J. Savides and K. G. Reseck, "GOES I-M system characteristics," in Program, GOES I-M Operational Satellite Conf., Arlington, VA, pp. 285-314, 1989.

[192] E. A. Kupcis, "The FAA sponsored windshear training aid," in Proc. Third Int. Conf. on the Aviation Weather System, Anaheim, CA, pp. 317-322, 1989.

[193] R. Jackson, "The aviation outreach program of Seattle WSFO," in Proc. Third Int. Conf. on the Aviation Weather System, Anaheim, CA, pp. 313-316, 1989.

[194] R. D. Roberts and J. W. Wilson, "A proposed microburst nowcasting procedure using single Doppler radar," J. Appl. Meteorol., vol. 28 , pp. 285-303, 1989

[195] —, "Nowcasting microbursts using Doppler radar in a forecaster-computer environment," in Proc. Symp. Mesoscale Analysis and Forecasting, Vancouver, Canada, European Space Agency SP-282, pp. 43-48, 1987.

[196] D. A. Chisholm, A. R. Bohne, and R. M. Dyer, "The development of numerically-based and expert system approaches for airfield nowcasting/very short range forecasting," in Proc. Third Int. Conf. on the Aviation Weather System, Anaheim, CA, pp. $433-436,1989$.

[197] S. D. Campbell, "Microburst precursor recognition using an expert system approach," in Proc. Amer. Meteor. Soc. 4th Int. Conf. on Interactive Information and Processing Systems for Meteorology, Oceanography and Hydrology, Anaheim, CA, p. $300,1988$.

[198] D. Giuli, "Polarization diversity in radars," Proc. IEEE, vol. 74 , pp. $245-269,1986$

[199] M Sachidananda and D. S. Zrnić, "Differential propagation phase shift and rainfall rate estimation," Radio Sci., vol. 21 , pp. 235-247, 1986 .

[200] R. M. Wakimoto and V. N. Bringi, "Operational detection of microbursts associated with intense convection: the $20 \mathrm{July}$ storm during the MIST project," Mon. Wea. Rev., vol. 116, pp. $1521-1539,1988$.

[201] N. Balakrishnan and D. S. Zrnić, "Use of polarization to characterize precipitation and discriminate large hail," J. Atmos. Sci., vol. 47, pp. $1525-1540,1990$.

[202] V. N. Bringi, T. A. Seliga, and K. Aydin, "Hail detection with a differential reflectivity radar," Science, vol. 225 , pp. $1145-1147,1984$.

[203] M. P. M. Hall, J. W. F. Goddard, and S. M. Cherry, "Identification of hydrometeors and other targets by dual-polarization radar," Radio Sci., vol. 19, pp. 132-140, 1984

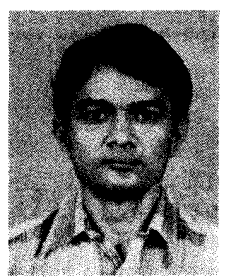

Pravas R. Mahapatra received the B.Sc. (Eng.) from Regional Engineering College at Rourkela, India and the M.E and Ph.D. degrees from the Indian Institute of Science at Bangalore, India.

Since 1970, he has been teaching at the Department of Aerospace Engineering in the Indian Institute of Science, where he is currently a professor. From 1980 to 1982 he was an NRC Research Associate at NOAA's National Severe Storms Laboratory (NSSL) in Norman, OK. In the summer of 1983 , he was with the University of Oklahoma, Norman. From 1989 to 1990 he returned to NSSL for a sabbatical year as a Senior Associate, studying several aspects of Doppler weather radars and other instrumentation, especially in relation to aviation management and safety. He has a broad area of active interest within the field of aerospace and electronic systems. This includes radar systems, aerospace navigation theory, navigational aids, and flight safety aspects with particular reference to weather phenomena and air traffic control. He has authored or coauthored about one-hundred scientific and technical papers, has reviewed numerous papers for major journals, and has received awards.

Dr. Mahapatra is a member of the U.S. Institute of Navigation.

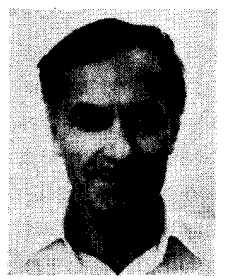

Dusan S. Zrnić (Fellow, IEEE) was born in Belgrade, Yugoslavia. He graduated from the University of Belgrade, with a Dipl. Ing. degree in electrical engineering in 1965. He received the M.S. and Ph.D. degrees in electrical engineering from the University of Illinois, Urbana, in 1966 and 1969 , respectively.

Following employment as a research and teaching assistant with the Charged Particle Research Laboratory at the University of Illinois, he joined the Electrical Engineering Department of the California State University. Northridge, where he became a professor in 1978. During the 1973-1974 academic year, he was a National Research Council Postdoctoral Fellow at the NSSL, and from 1975-1976 he was on sabbatical research leave from California State University at the same laboratory. Currently, he is Chief of the Doppler Radar and Remote Sensing Research group at the National Severe Storms Laboratory (NSSL). He is also Adjunct Professor of electrical engineering and metrology at the University of Oklahoma, Norman. His research experience includes circuit design, applied mathematics, magnetohydrodynamics, radar signal processing, and systems design. During the last fifteen years the thrust of his effort was in improvements of weather radar signal processing advancements of polarimetric measurements and their interpretation, and development of algorithms for NEXRAD. He has published extensively in scientific and engineering journals and is Associate Editor of the Journal of Atmospheric and Oceanic Technology.

Dr. Zrnić has been a member of URSI Commissions C and F since 1976 and he is a member of the AMS. He has twice been awarded the Best Research Paper Award by the Environmental Research Laboratories. He is also a corecipient of the IEEE 1988 Harry Diamond Memorial Award for contributions to and applications of weather radar science. 